\title{
Erk regulation of pyruvate dehydrogenase flux through PDK4 modulates cell proliferation
}

\author{
Alexandra R. Grassian, ${ }^{1,4}$ Christian M. Metallo, ${ }^{2,3,4}$ Jonathan L. Coloff, ${ }^{1}$ Gregory Stephanopoulos, ${ }^{2}$ \\ and Joan S. Brugge ${ }^{1,5}$ \\ ${ }^{1}$ Department of Cell Biology, Harvard Medical School, Boston, Massachusetts 02115, USA; ${ }^{2}$ Department of Chemical \\ Engineering, Massachusetts Institute of Technology, Cambridge, Massachusetts 02139, USA
}

Loss of extracellular matrix (ECM) attachment leads to metabolic impairments that limit cellular energy production. Characterization of the metabolic alterations induced by ECM detachment revealed a dramatic decrease in uptake of glucose, glutamine, and pyruvate, and a consequent decrease in flux through glycolysis, the pentose phosphate pathway, and the tricarboxylic acid (TCA) cycle. However, flux through pyruvate dehydrogenase (PDH) is disproportionally decreased, concomitant with increased expression of the PDH inhibitory kinase, PDH kinase 4 (PDK4), and increased carbon secretion. Overexpression of ErbB2 maintains PDH flux by suppressing PDK4 expression in an Erk-dependent manner, and Erk signaling also regulates PDH flux in ECMattached cells. Additionally, epidermal growth factor (EGF), a potent inducer of Erk, positively regulates PDH flux through decreased PDK4 expression. Furthermore, overexpression of PDK4 in ECM-detached cells suppresses the ErbB2-mediated rescue of ATP levels, and in attached cells, PDK4 overexpression decreases PDH flux, de novo lipogenesis, and cell proliferation. Mining of microarray data from human tumor data sets revealed that PDK4 mRNA is commonly down-regulated in tumors compared with their tissues of origin. These results identify a novel mechanism by which ECM attachment, growth factors, and oncogenes modulate the metabolic fate of glucose by controlling PDK4 expression and PDH flux to influence proliferation.

[Keywords: metabolism; glucose; extracellular matrix; pyruvate dehydrogenase; Erk; lipogenesis]

Supplemental material is available for this article.

Received April 10, 2011; revised version accepted July 12, 2011.

Tumor cell survival in altered matrix environments is believed to be important in both early and late stages of cancer development. In early premalignant lesions, excessive proliferation displaces cells from their natural extracellular matrix (ECM) environments; as tumors progress, they must adapt to survive in distinct ECM niches during invasion into foreign tissue environments, intravasation into blood vessels, and extravasation to distant tissue sites. Studies of cultured cells have demonstrated that normal epithelial cells require attachment to matrix to survive and proliferate (Frisch and Screaton 2001; Horbinski et al. 2010), whereas cultured tumor cell lines or oncogene-transformed cells are often able to survive and proliferate in an anchorage-independent manner (Macpherson and Montagnier 1964; Chiarugi and Giannoni 2008; Horbinski et al. 2010; Hanahan and Weinberg 2011). This distinction between the

\footnotetext{
${ }^{3}$ Present address: Department of Bioengineering, University of California at San Diego, 9500 Gilman Drive, La Jolla, California 92093, USA.

${ }^{4}$ These authors contributed equally to this work.

${ }^{5}$ Corresponding author.

E-mail joan_brugge@hms.harvard.edu.

Article is online at http://www.genesdev.org/cgi/doi/10.1101/gad.16771811.
}

behavior of normal and tumorigenic/transformed cells suggests that tumor cells undergo selection for "anchorage independence" during tumorigenesis (Macpherson and Montagnier 1964). Thus, it is critical to gain a deeper understanding of the mechanistic basis for the requirement of ECM attachment by normal epithelial cells and for the ability of tumor cells to overcome this dependence.

Normal epithelial cells undergo a caspase-dependent, apoptotic death, termed "anoikis," when deprived of ECM (Frisch and Screaton 2001; Horbinski et al. 2010). However, we showed previously that inhibition of apoptosis alone is not sufficient to maintain cell survival under these conditions because matrix detachment also causes a metabolic impairment, limiting ATP production (Debnath et al. 2002; Mailleux et al. 2007; Schafer et al. 2009). We observed that ECM detachment of immortalized, nontumorigenic mammary epithelial cells (MCF-10A cells) causes a decrease in ATP levels associated with a significant reduction in glucose uptake, due at least in part to decreased activation of the PI3K/Akt pathway. Importantly, overexpression of the ErbB2 oncogene, which is amplified in $25 \%$ of breast tumors (Hynes and Lane 2005), 
rescues survival under ECM-detached conditions and significantly reverses the decrease in glucose uptake and ATP levels under detached conditions.

Initial characterizations of the ECM detachment-induced metabolic defect included measurements of ATP levels and glucose uptake. However, other nutrients and flux through numerous metabolic pathways are required to supply energy, regenerate cofactors, and synthesize biomass in proliferating cells (DeBerardinis et al. 2008b; Wise et al. 2008; Metallo et al. 2009; Vander Heiden et al. 2009; Weinberg et al. 2010; Wellen and Thompson 2010; Wellen et al. 2010). As such, we were interested in further characterizing the metabolic changes induced by ECM detachment and ErbB2 overexpression.

In particular, the tricarboxylic acid (TCA) cycle provides an efficient means of producing ATP and many biosynthetic intermediates. A key regulator of TCA cycle flux is the pyruvate dehydrogenase $(\mathrm{PDH})$ complex, which catalyzes the conversion of pyruvate into acetyl coenzyme A (AcCoA) and thus regulates the entry of glucose-derived carbons into the TCA cycle. PDH flux is regulated in part by $\mathrm{PDH}$ kinases (PDKs), of which there are four isoenzymes: PDK1-4 (Sugden and Holness 2006; Roche and Hiromasa 2007; McFate et al. 2008). PDK can phosphorylate and inactivate the catalytic subunit of $\mathrm{PDH}$ at up to three different residues (Michelakis et al. 2008). PDK1 transcription is stimulated by low oxygen levels (Kim et al. 2006; Papandreou et al. 2006), and PDK4 expression can be induced by nutrient deprivation, high-fat diet, and diabetes (Roche and Hiromasa 2007). PDK2 levels are also increased under low-nutrient conditions (Sugden et al. 1998, 1999; $\mathrm{Wu}$ et al. 2000). Increased PDK expression under these conditions allows for preferential oxidation of fatty acids, and promotes the utilization of alternative carbon sources for gluconeogenesis (Roche and Hiromasa 2007). Thus, system-level analyses are required to understand the complex regulation of glycolysis, the TCA cycle, and PDH flux by mitogenic, oncogenic, and environmental factors.

${ }^{13} \mathrm{C}$ metabolic flux analysis (MFA) provides an effective means of quantifying metabolic pathway utilization in mammalian cells (Boros et al. 2003; Munger et al. 2008; Zamboni 2011). The use of isotopic tracers, system-level data acquisition, and computational modeling allows for the estimation of fluxes and associated confidence intervals, which are the most representative characterization of in vivo enzyme function (Antoniewicz et al. 2006; Metallo et al. 2009). Such analyses enable the identification of key regulatory points in perturbed cellular systems, and when applied to the appropriate systems, these techniques can help characterize how signaling pathways and microenvironments regulate metabolic processes.

In this study, we analyzed alterations in nutrient uptake and metabolic flux to better define the metabolic impairments associated with loss of matrix attachment. We found that matrix detachment decreases uptake of nutrients, as well as flux through numerous metabolic pathways including glycolysis, the pentose phosphate pathway (PPP), and the TCA cycle. Interestingly, PDH flux is disproportionately decreased after ECM detachment. We found that ECM attachment and ErbB2, through Erk signaling, positively regulate flux through the PDH complex by inhibiting PDK4 expression. Additionally, we show that PDK4 expression is an important regulator of ATP levels, de novo lipogenesis, and cell proliferation, and that PDK4 mRNA levels are decreased in a variety of tumors. These results identify a novel mechanism by which ECM attachment and growth factors regulate essential metabolic fluxes through Erk signaling and demonstrate how Erk modulation of PDH flux can influence proliferation of epithelial cells. Additionally, these results suggest one potential mechanism by which aberrant Erk signaling could contribute to the regulation of tumor cell proliferation through changes in cellular metabolism.

\section{Results}

\section{ECM-detached cells are nutrient-starved}

We previously demonstrated that ECM detachment of mammary epithelial cells results in a dramatic reduction in glucose uptake and cellular ATP levels (Schafer et al. 2009). To further investigate the metabolic alterations associated with ECM attachment and how ErbB2 rescues cells from this metabolic impairment, we examined the uptake of three key carbon sources (glucose, glutamine, and pyruvate) by MCF-10A cells after $24 \mathrm{~h}$ of culture under ECM-attached or ECM-detached conditions. Net uptake of each was decreased $30 \%-60 \%$ in MCF-10A cells after ECM detachment, and overexpression of ErbB2 (MCF-10A ErbB2) partially rescued these reductions (Fig. $1 \mathrm{~A}-\mathrm{C})$. Consistent with the net decrease in glucose uptake observed in suspended cells, we detected a marked drop in the nonoxidative glycolytic product lactate under these conditions (Fig. 1D). Surprisingly, despite this net decrease in lactate secretion, we calculated a significant increase in the ratio of secreted lactate to glucose uptake after ECM detachment (Fig. 1E), demonstrating that detached cells produce more lactate per glucose molecule consumed than do attached cells. These results suggested that matrix-detached MCF-10A cells preferentially divert pyruvate toward lactate rather than the TCA cycle, and this may contribute to the observed decrease in ATP levels under these conditions. Notably, MCF-10A ErbB2 cells, which maintain ATP levels in ECM-detached conditions (Schafer et al. 2009), do not exhibit an increase in the lactate/glucose ratio.

The changes in nutrient uptake and the lactate/glucose ratio suggest that ECM detachment and ErbB2 overexpression may alter metabolic fluxes. To examine changes in intracellular metabolic pathways, MCF-10A and MCF10A ErbB2 cells were cultured under attached or detached conditions with $\left[1,2-{ }^{13} \mathrm{C}_{2}\right]$ glucose (labeled on the first and second carbon only) for $24 \mathrm{~h}$ before extraction and quantification of the abundance of isotopic label in metabolites via gas chromatography/mass spectrometry (GC/MS). In order to account for changes in both extracellular fluxes as well as isotopic labeling in all intermediates, we performed ${ }^{13} \mathrm{C}$ MFA to determine fluxes and associated confidence intervals in a basic network describing central carbon metabolism. Globally, we observed that ECM detachment 
A
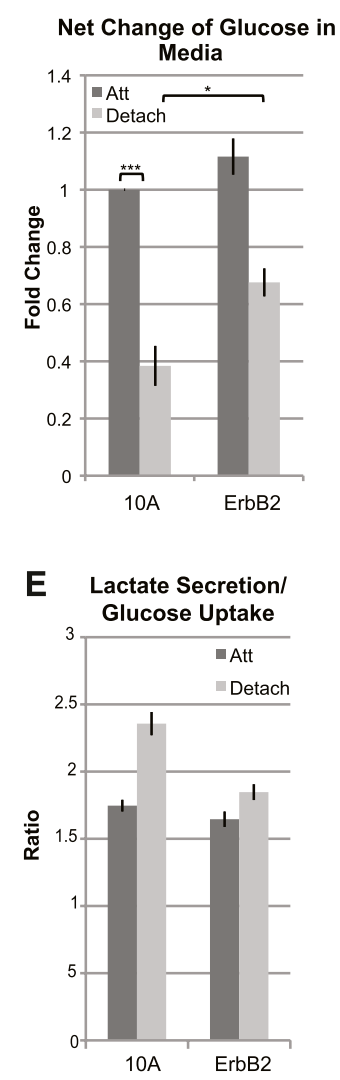

B

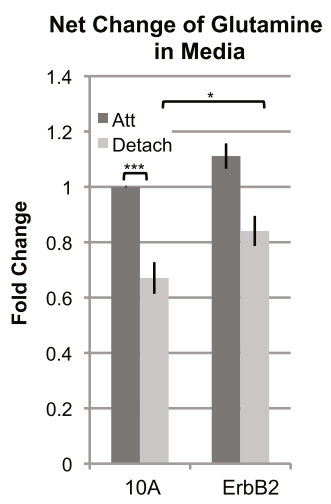

F

MCF-10A Detach vs. Att Cells

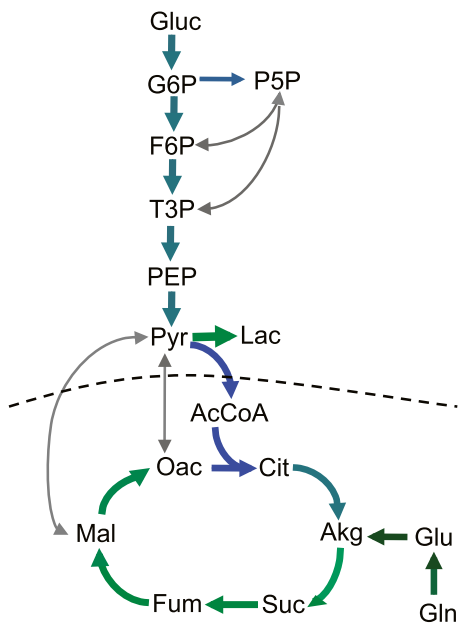

D

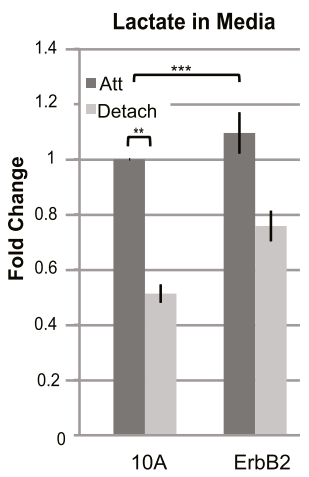

MCF-10A ErbB2 Detach vs. MCF-10A Detach Cells

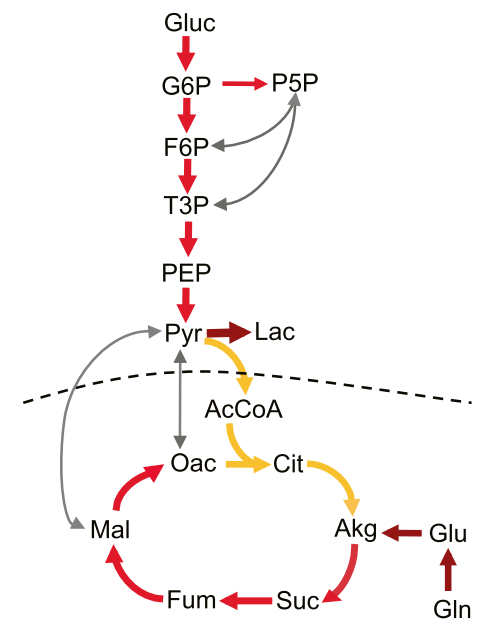

Metabolite Flux in MCF-10A Attached Cells (pmol/cell/hr)

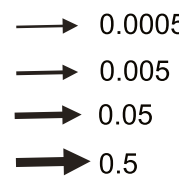

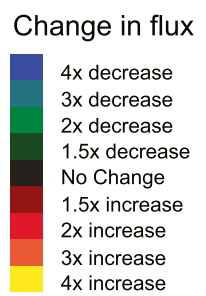

Figure 1. Changes in nutrient uptake induced by ECM detachment and ErbB2 overexpression. $(A-D)$ MCF-10A or MCF-10A ErbB2 cells were cultured on control (Att) or polyHEMA-coated plates (Detach) for 24 h. Changes in glucose $(A)$, glutamine $(B)$, pyruvate $(C)$, and lactate $(D)$ medium concentration were normalized to attached MCF-10A cells. Data are presented as an average from three or more independent experiments. $(E)$ Ratio of lactate secretion to glucose uptake. $(F)$ Graphical representation of fluxes determined via MFA or MID data (for oxidative PPP). Arrow thickness indicates level of flux in MCF-10A-attached cells. Color indicates fold difference between detached and attached MCF-10A cells (left panel) or between detached MCF-10A ErbB2 and detached MCF-10A cells (right panel). Gray arrows indicate fluxes not determined. (Akg) $\alpha$-Ketoglutarate; (Asp) aspartate; (Cit) citrate; (Fum) fumarate; (F6P) fructose6-phosphate; (Gluc) glucose; (Glu) glutamate; (G6P) glucose-6-phosphate; (Gln) glutamine; (Lac) lactate; (Mal) malate; (Oac) oxaloacetate; (P5P) pentose-5-phosphate; (PEP) phosphoenolpyruvate; (Pyr) pyruvate; (Suc) succinate; (T3P) triose phosphate. See also Supplemental Figure S1 and Supplemental Table S1 for details of MFA model, results, and data.

of MCF-10A cells led to a striking decrease in flux through glycolysis, the PPP, and the TCA cycle (schematic summary shown in Fig. 1F; flux data in Supplemental Table S1 and Supplemental Fig. S1). Importantly, ErbB2 overexpression significantly rescued the flux through these pathways in the ECM-detached cells.

\section{ErbB2 prevents a decrease in PDH and TCA flux after ECM detachment}

The increase in the lactate/glucose ratio indicates that MCF-10A-detached cells may divert a greater percentage of carbons away from the TCA cycle. To monitor pyruvate 
entry into the TCA cycle, we examined the ${ }^{13} \mathrm{C}$-labeling patterns of various metabolites (designated as MO, M1, and M2 mass isotopomers, corresponding to ion fragments containing zero, one, or two carbons, respectively). Metabolism of $\left[1,2-{ }^{13} \mathrm{C}_{2}\right]$ glucose through glycolysis and the TCA cycle primarily generates M0 and M2 pyruvate, AcCoA, and TCA intermediates (Fig. 2A, left panel). Therefore, the ratio of M2 labeling of TCA intermediates to M2 pyruvate provides an indication of the relative level of pyruvate oxidation by PDH. Importantly, these normalized measurements are independent of the nutrient uptake measurements used to calculate the ratios in Figure 1E. Consistent with the increased lactate to glucose ratio in the MCF-10Adetached cells, we found that the ratio of M2 citrate, glutamate (derived from $\alpha$-ketoglutarate), fumarate, or aspartate (derived from oxaloacetate) to M2 pyruvate decreased after ECM detachment (Fig. 2A, right panel), indicative of a decreased percentage of pyruvate entering the TCA cycle. M4 and M3 labeling of TCA intermediates results from entry of a second M2 AcCoA into the TCA cycle (Fig. 2B, left panel) and thus provides an additional indicator of PDH flux that is independent of pyruvate carboxylase activity. As with the M2/M2 pyruvate ratio, M4 citrate and glutamate or M3 fumarate and aspartate to M2 pyruvate also decreased in MCF-10A ECM-detached cells (Fig. 2B, right panel). ErbB2 overexpression partially prevented the decrease of these ratios, indicating that ErbB2 maintains higher PDH flux in ECM-detached cells.

Consistent with the mass isotopomer ratio data, we observed a decrease in PDH flux in MCF-10A-detached cells, which was almost completely reversed by ErbB2 overexpression (Fig. 2C). The decrease in PDH flux correlated with a decrease in flux through the oxidative TCA cycle (Supplemental Fig. S2A). Levels of TCA intermediates also decreased in MCF-10A-detached cells (Supplemental Fig. S2B). In contrast, MCF-10A ErbB2 cells maintained higher TCA flux and levels of TCA intermediates. Thus, the decrease in PDH flux after ECM detachment likely contributes to a reduction of TCA flux and intermediates under detached conditions. Trends in LDH flux were similar to that for PDH flux (Fig. 2D); however, as with the lactate to glucose ratio, the ratio of LDH to PDH flux increased in the MCF-10A-detached, but not MCF-10A ErbB2-detached, cells (Fig. 2E).

Glutamine is also an important cataplerotic and anaplerotic source of carbon for the TCA cycle. To monitor the relative contribution of glutamine to TCA cycle intermediates, we cultured MCF-10A and MCF-10A ErbB2 cells with $\left[\mathrm{U}^{13} \mathrm{C}_{5}\right]$ glutamine and measured the percent labeling of TCA intermediates (Supplemental Fig. S2C-F). We found that the percent of TCA intermediates derived from glutamine were either decreased or unchanged after matrix detachment of the MCF-10A cells, demonstrating that glutamine metabolism does not rescue the decreased glucose flux through the TCA cycle in response to matrix detachment.

We then sought to determine how pyruvate utilization changes in greater detail, as pyruvate can be both taken up and secreted by cells. The measurements of the net change in pyruvate concentration in the medium in
Figure 1C do not differentiate between changes in pyruvate uptake and secretion. To specifically measure pyruvate uptake and secretion, we cultured cells in medium containing $100 \%\left[2-{ }^{13} \mathrm{C}\right]$ pyruvate (with all other nutrients unlabeled) and measured the concentration and labeling of pyruvate in the medium after $24 \mathrm{~h}$. Use of the ${ }^{13} \mathrm{C}$-labeled pyruvate allows us to better differentiate between uptake and secretion; the decrease in M1 pyruvate concentration in the medium provides a readout for pyruvate uptake, whereas the concentration of M0 pyruvate in the spent medium (which can only be produced by the cell from other unlabeled nutrients, such as glucose) provides an indication of pyruvate secretion. We observed a small decrease in net consumption of M1 pyruvate in the MCF-10A-detached cells, which was partially rescued by ErbB2 overexpression (Fig. 2F). Surprisingly, we saw a dramatic increase in pyruvate secretion in the MCF-10A-detached cells, and ErbB2 overexpression partially prevented this increase (Fig. 2G). We made similar calculations based on analysis of M1 and M2 pyruvate levels in spent medium obtained from cells cultured with $\left[1,2-{ }^{13} \mathrm{C}_{2}\right]$ glucose and unlabeled pyruvate, and observed the same trends as described above (Supplemental Fig. S2G). Pyruvate can also be converted to alanine by cytosolic and mitochondrial transaminases; alanine levels were elevated in spent medium from cultures of ECM-detached MCF-10A cells (Supplemental Fig. S2H). Therefore, ECM detachment results in a decrease in PDH flux, along with a decrease in TCA flux and an increase in pyruvate secretion, all of which can be partially rescued by ErbB2 overexpression.

\section{PDK4 expression is regulated by ECM attachment} and Erk

PDH flux is controlled in part by PDKs (PDK1, PDK2, PDK3, and PDK4), which phosphorylate and inactivate PDH. Examination of mRNA microarray data from matrixattached and -detached MCF-10A cells revealed a dramatic and specific increase in the levels of PDK4 mRNA in matrix-detached cells (Supplemental Fig. S3A). Neither PDK1, PDK2, nor PDK3 showed a significant increase in detached cells. Using quantitative real-time PCR (qPCR), we determined that ECM detachment resulted in a 25 -fold to 30-fold increase in PDK4 mRNA, which was partially mitigated by ErbB2 overexpression (Fig. 3A). PDK4 protein levels displayed similar changes (Fig. 3B). Matrix detachment of two additional nontransformed mammary epithelial cell lines (human mammary epithelial cells [HMECs] hTERT and HC11) also led to increased PDK4 mRNA (Supplemental Fig. S3B,C). To examine whether PDK4 upregulation contributed to the decreased PDH flux in matrix detached cells, we knocked down PDK4 expression using two independent shRNAs (Fig. 3C). Both PDK4-targeted shRNAs caused increased relative flux through $\mathrm{PDH}$ in the MCF-10A-detached cells (Fig. 3D), demonstrating that the up-regulation of PDK4 is at least in part responsible for the decrease in PDH flux in the detached cells.

To examine whether ErbB2 negatively regulates PDK4 levels in other cell lines, we quantified PDK4 levels in a set of mouse mammary epithelial cells. The control, 
Grassian et al.
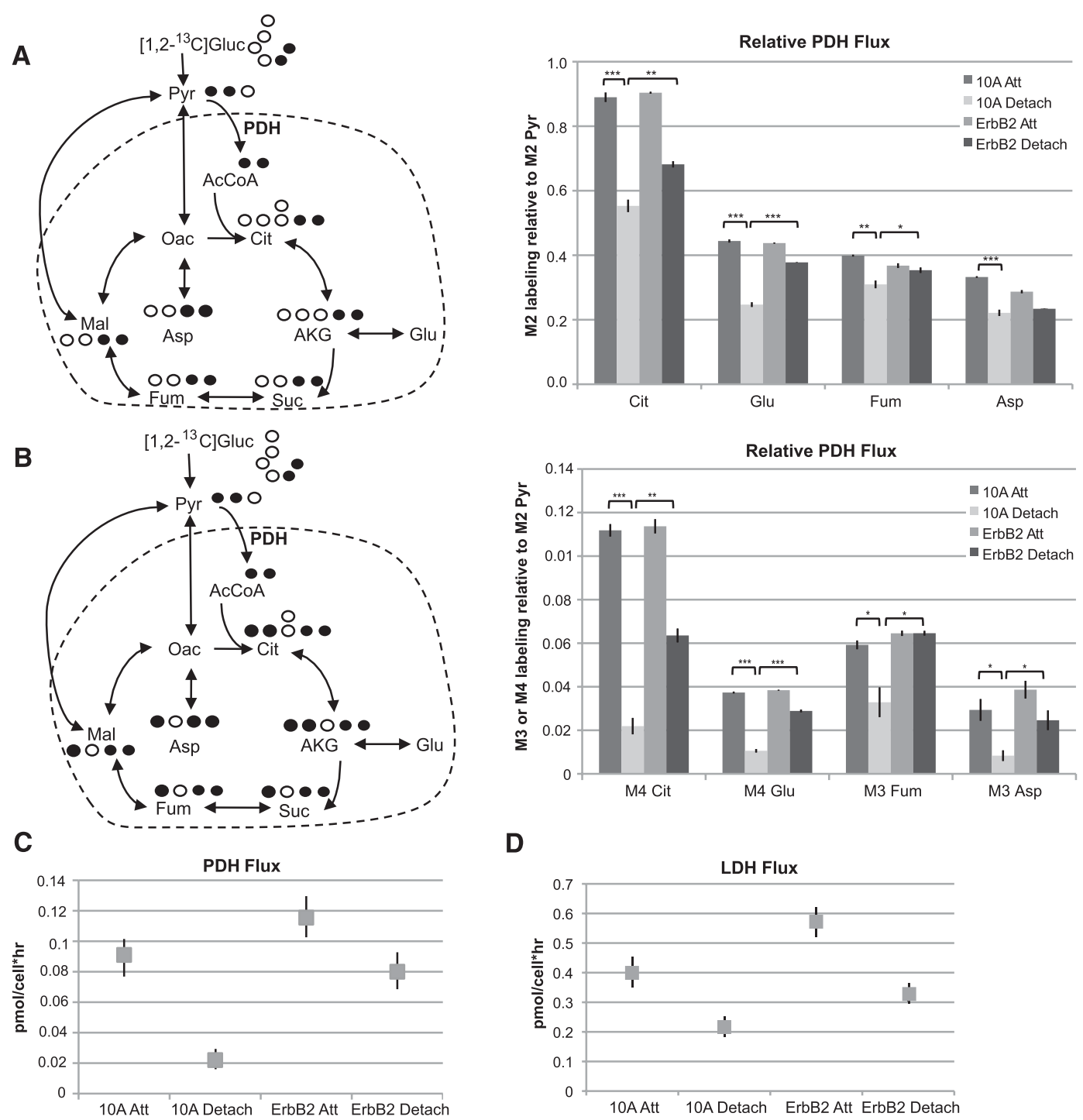

D
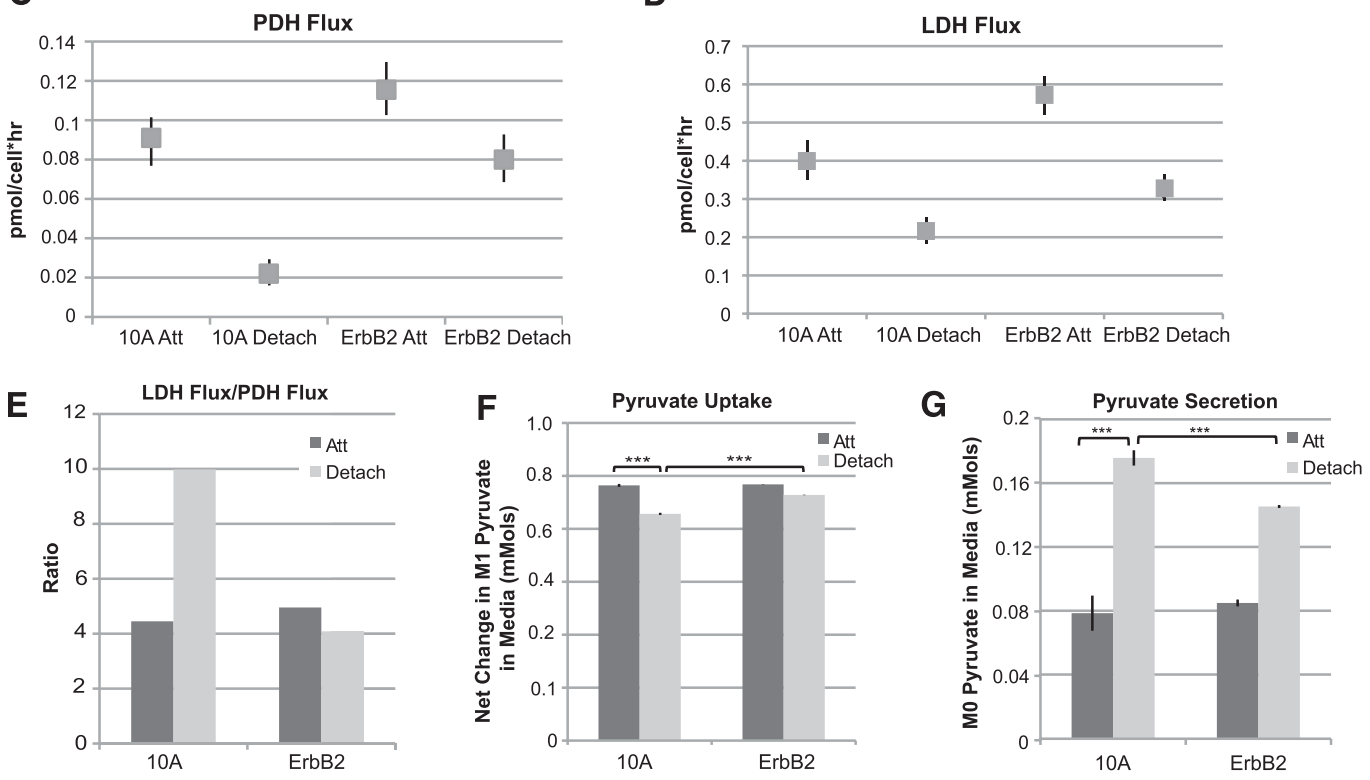

Figure 2. ErbB2 maintains PDH flux in ECM-detached cells. (A, left panel) Carbon atom (represented by circles) transitions and tracers used to detect the changes in PDH flux. Using isotopic label from $\left[1,2-{ }^{13} \mathrm{C}_{2}\right]$ glucose (black circles). (Right panel) Cells were cultured with $\left[1,2-{ }^{13} \mathrm{C}_{2}\right]$ glucose as in Figure 1A. Relative PDH flux was estimated by calculating the ratio of M2 citrate (Cit), glutamate (Glu), fumarate (Fum), or aspartate (Asp) normalized to M2 pyruvate labeling, which was determined by GC/MS. Data are representative of three independent experiments. (B) The left panel shows entry of second M2 AcCoA into the TCA cycle. (Right panel) Ratio of M4 citrate or glutamate, or M3 fumarate or aspartate, to M2 pyruvate. Data are representative of three independent experiments. $(C, D)$ $\mathrm{PDH}(C)$ and $\mathrm{LDH}(D)$ flux estimates and $95 \%$ confidence intervals by the ${ }^{13} \mathrm{C}$ MFA model. Data are representative of three independent experiments. $(E)$ Ratio of values in $C$ and $D .(F, G)$ Pyruvate uptake $(F)$ and synthesis/secretion $(G)$ were determined by measuring the concentration of labeled and unlabeled pyruvate in spent medium from cells cultured with $\left[2-{ }^{13} \mathrm{C}\right]$ pyruvate in triplicate, and average values are presented. 


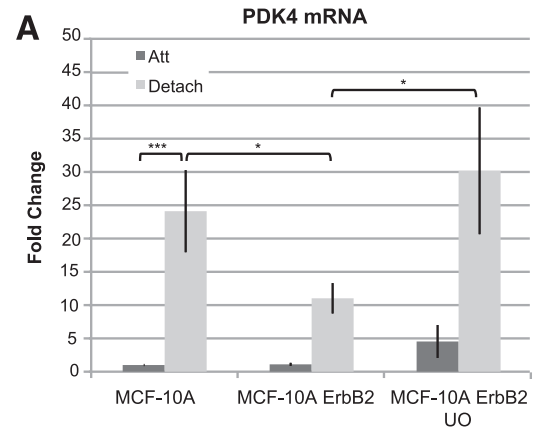

C
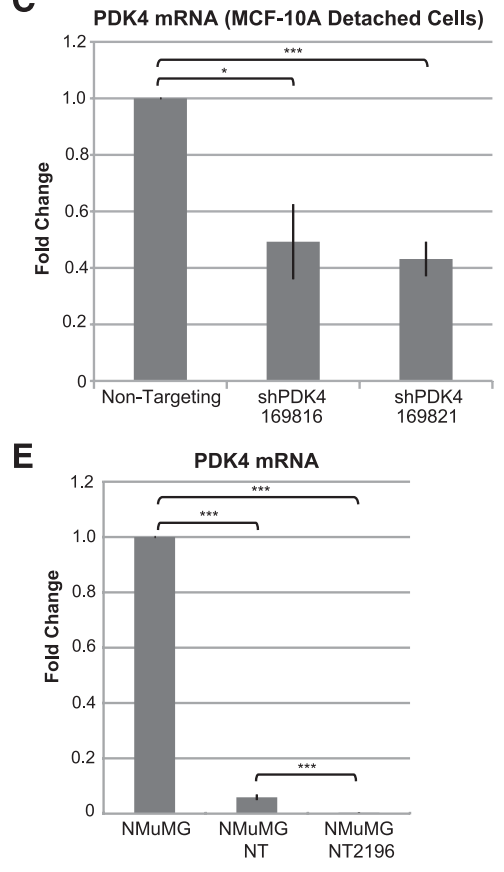

H

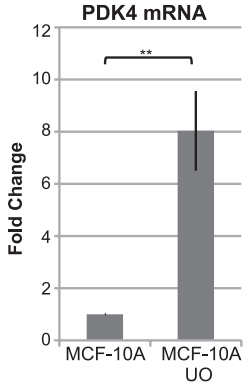

B
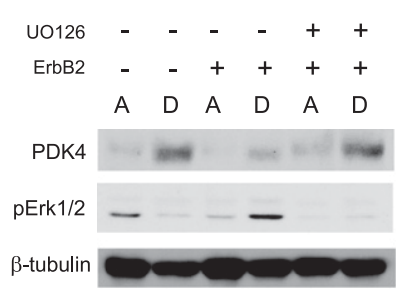

D
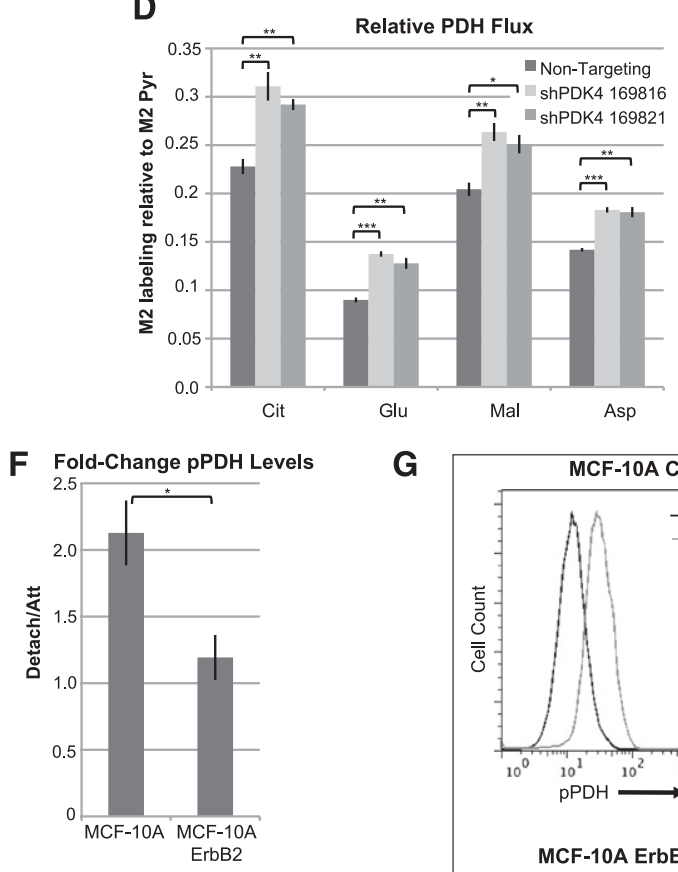

G

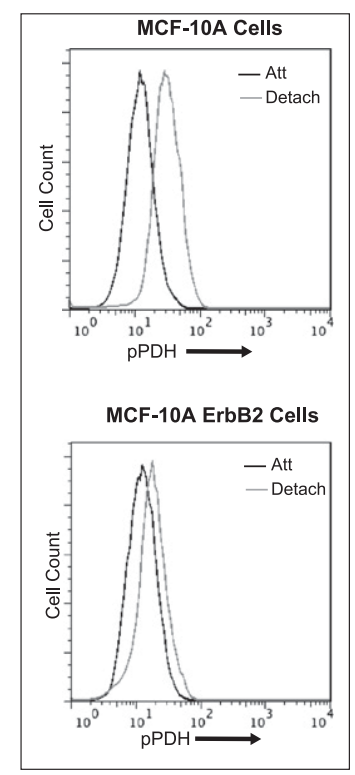

Figure 3. PDK4 expression is regulated by ECM attachment and Mek/Erk signaling. (A) MCF-10A cells, or MCF-10A ErbB2 cells treated with $10 \mu \mathrm{M}$ UO126 (UO) or vehicle, were plated in attached or detached conditions. Twenty-four hours later, mRNA levels for PDK4 were quantified by qPCR. (B) Cells were plated as in $A$ in attached (A) or detached (D) conditions with vehicle control or $10 \mu \mathrm{M} U O 126$ (UO). Expression or phosphorylation of the indicated proteins was determined by immunoblotting. $(C)$ MCF-10A cells were infected with nontargeting or PDK4-targeting doxycycline-inducible small hairpins (shRNAs). Expression of the shRNA was induced for $48 \mathrm{~h}$ with $1 \mu \mathrm{g} /$ $\mathrm{mL}$ doxycycline. Cells were then grown in detached conditions in the presence of $1 \mu \mathrm{g} / \mathrm{mL}$ doxycycline for $24 \mathrm{~h}$. PDK4 mRNA levels were determined by qPCR. Data are presented as fold change relative to MCF-10A-detached cells with nontargeting shRNA. (D) Cells were grown as in $C$ in the presence of $\left[1,2-{ }^{13} \mathrm{C}_{2}\right]$ glucose for $24 \mathrm{~h}$. Relative $\mathrm{PDH}$ flux was estimated by calculating the ratio of M2 citrate (Cit), glutamate (Glu), malate (Mal), or aspartate (Asp) normalized to M2 pyruvate labeling, which was determined by GC/MS. (E) Expression of PDK4 in NMuMG, NMuMG Neu-T (NT), and NMuMG NT2196 cells was determined by qPCR. Data are an average of three independent experiments and are presented as fold change relative to NMuMG cells. $(F, G)$ MCF-10A cells or MCF-10A ErbB2 cells were plated in attached or detached conditions. Twenty-four hours later, the level of pSer293 PDH was determined by flow cytometry. Data are presented as fold change over attached cells, and are an average of three independent experiments $(F)$ or representative of three independent experiments $(G)$. $(H)$ MCF-10A cells treated with $10 \mu \mathrm{M}$ UO126 (UO) or vehicle were plated and analyzed as in $A$. Data shown in $A$ and $H$ are presented as average fold increases relative to MCF-10A-attached cells from three independent experiments. 
nontumorigenic NMuMG cells express high PDK4 levels in attached conditions (Fig. 3E). Overexpression of constitutively active ErbB2 (Neu-T) decreased PDK4 mRNA by $\sim 17$-fold in the NMuMG cells. Interestingly, PDK4 levels were further suppressed in NMuMG Neu-T cells explanted from xenografts (undetectable by qPCR).

PDK4 phosphorylates PDH on Ser 293 (Rardin et al. 2009|. To examine whether the increased PDK4 levels in matrix-detached cells are associated with increased PDH phosphorylation at this site, we examined pS293 PDH levels by flow cytometry. Detachment of MCF-10A cells leads to a large increase in pS293 PDH levels, whereas ErbB2 overexpression reduced the level of phosphorylation induced by matrix detachment (Fig. 3F,G), correlating with the changes in PDK4 expression (Fig. 3A,B). The increase in pS293 PDH levels in the ECM-detached MCF-10A cells was prevented by knockdown of PDK4 (Supplemental Fig. S3D). Expression of the PDH phosphatases (PDH phosphatase catalytic subunit 2 [PDP-1], $\mathrm{PDH}$ phosphatase isoenzyme 2 [PDP-2], and $\mathrm{PDH}$ regulatory subunit [PDPR]) was not greatly affected by matrix detachment, and does not correlate with the observed changes in PDH activity or phosphorylation (Supplemental Fig. S3E).

PDK4 mRNA levels have previously been shown to be negatively regulated by PI3K/Akt signaling in muscle cells, as the PI3K/mTor inhibitor LY294002 increased PDK4 levels in these cells (Puthanveetil et al. 2010). Since ErbB2 maintains Akt activation in ECM-detached cells (Schafer et al. 2009), we sought to determine whether ErbB2, through maintenance of PI3K/Akt signaling, suppresses PDK4 levels in ECM-detached MCF-10A cells. Treatment of the MCF10A ErbB2 cells with LY294002 did not prevent the ErbB2 maintenance of low PDK4 levels after ECM detachment (Supplemental Fig. S3F), suggesting that the ErbB2 regulation of PDK4 is independent of PI3K/Akt signaling. ErbB2 also maintains activation of the Mek/Erk pathway in ECMdetached cells (Reginato et al. 2003; Schafer et al. 2009; Grassian et al. 2011), and treatment of MCF-10A ErbB2 cells with either of two Mek inhibitors (UO126 and PD98059) increased PDK4 mRNA and protein levels under ECMdetached conditions (Figs. 3A,B; Supplemental Fig. S3G). MCF-10A cells and HMECs plated in attached conditions also displayed increased PDK4 mRNA levels with Mek inhibition (Fig. 3H; Supplemental Fig. S3H,I). A Mek1/ 2-specific inhibitor, PD184352 (which does not inhibit Mek5/Erk5 at $1 \mu \mathrm{M}$ ) (Mody et al. 2001), also increased PDK4 levels in the MCF-10A-attached cells (Supplemental Fig. S3J). Interestingly, inhibition of either PI3K/Akt or Mek decreased PDK1 mRNA levels (Supplemental Fig. S3K), suggesting specific negative regulation of PDK4 by Erk. Thus, both ECM attachment and ErbB2 suppress PDK4 levels through Erk activity.

\section{Erk signaling regulates pyruvate metabolism}

As both Erk inhibition and ECM detachment result in increased PDK4 levels, we examined whether Erk inhibition would cause similar changes in pyruvate metabolism as ECM detachment. MCF-10A cells cultured in $\left[1,2-{ }^{13} \mathrm{C}_{2}\right]$ glucose with or without the Mek inhibitor UO126 showed that Mek/Erk inhibition decreased relative PDH flux (Fig. 4A); additionally, immunofluorescence staining of the MCF-10A-attached cells revealed that Erk inhibition leads to an increase in the percentage of cells with high levels of pS293 PDH (Fig. 4B; Supplemental Fig. S4A). Mek inhibition also decreased the net uptake of pyruvate in both MCF-10A-attached and MCF-10A ErbB2attached and -detached cells (Fig. 4C,D). Importantly, we found that, as with ECM detachment, the decrease in net pyruvate uptake induced by Mek inhibition was due in part to increased pyruvate secretion (Fig. 4E), indicating that Mek inhibition causes cells to divert carbon away from the TCA cycle.

Mek inhibition could also affect nutrient uptake; however, we did not detect a significant decrease in glucose or glutamine uptake in MCF-10A or MCF-10A ErbB2 cells treated with the Mek inhibitor UO126 at concentrations that decreased Erk activity by $50 \%$ or more (Fig. 4F,G; Grassian et al. 2011). This is consistent with a previous report showing that glucose uptake is insensitive to Mek inhibition (Lazar et al. 1995). As predicted, inhibition of PI3K, a key positive regulator of nutrient uptake (Plas et al. 2001; Edinger and Thompson 2002; Rathmell et al. 2003; Schafer et al. 2009|, decreased uptake of glucose, glutamine, and pyruvate in the MCF-10A ErbB2-attached and -detached cells (Supplemental Figs. S4B-D). Together, these results demonstrate that Mek inhibition causes a decrease in PDH activity and a concomitant increase in pyruvate secretion, without significant affects on nutrient uptake.

Insulin and epidermal growth factor (EGF) differentially regulate PDK4 levels and nutrient uptake

Recent data from our laboratory have shown that the EGF and insulin display differential ability to induce proliferation and to activate the PI3K/Akt and Mek/Erk pathways in MCF-10A cells; EGF alone induces strong Erk activation and proliferation, whereas insulin alone is a very weak inducer of Erk and is unable to induce proliferation (D Worster, J, Albeck, and JS Brugge, unpubl.; data not shown). The differences in proliferation and pathway activation by these two growth factors provided a useful context to examine the regulation of PDK4 by Erk and growth factors under normal conditions of monolayer cell growth. Figure 5A shows steady-state levels of Erk and Akt activation under conditions in which cells were either deprived of both growth factors, treated with each alone, or treated with both together for $24 \mathrm{~h}$. Withdrawal of both insulin and EGF from attached MCF-10A cells decreased Erk and Akt phosphorylation, as expected (Fig. 5A). Addition of insulin alone did not induce significant detectable sustained activation of either Erk or PI3K, although short-term stimulation with insulin did lead to increased levels of pAkt (Supplemental Fig. S5A). In contrast, EGF led to robust Erk activation under either condition (Fig. 5A; Supplemental Fig. S5A). While both factors were required for maximal activation of $\mathrm{Akt}$, addition of insulin did not further augment EGF-mediated activation of Erk. PDK4 mRNA levels correlated with Erk 
A

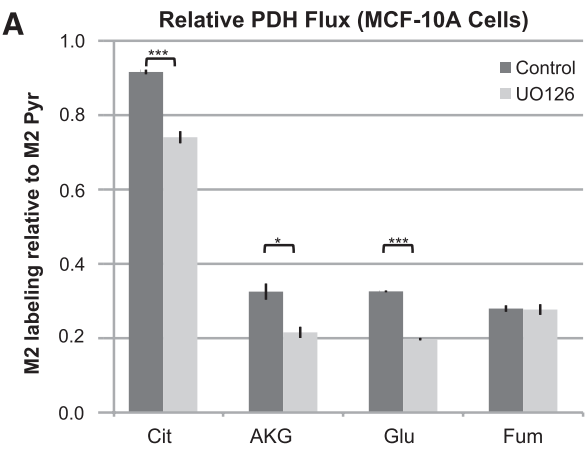

C

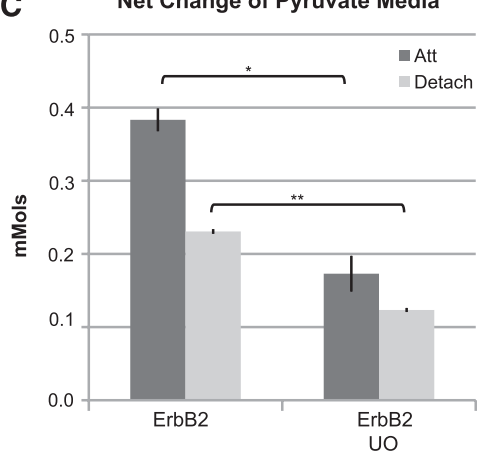

E
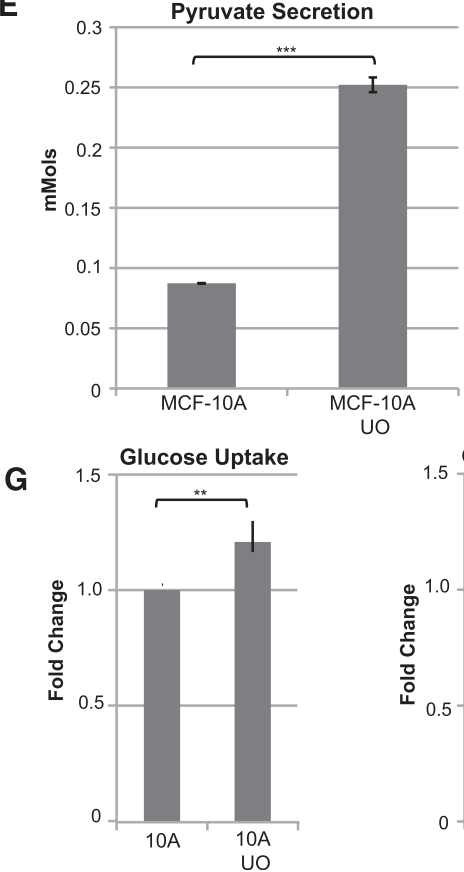

B

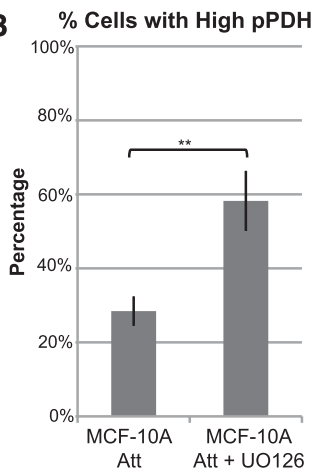

D

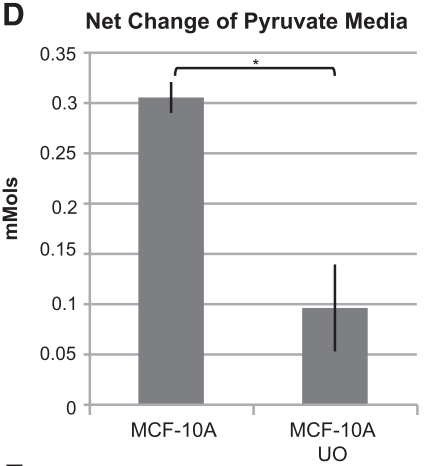

$\mathbf{F}$
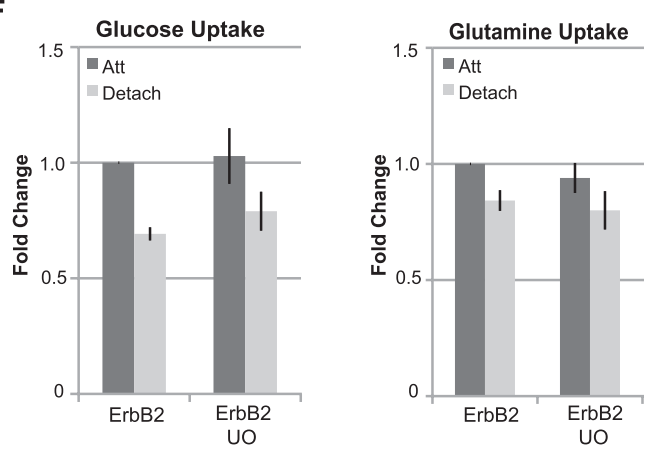

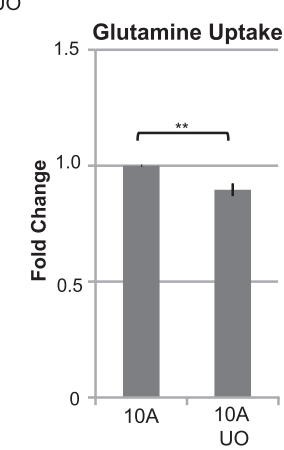

Figure 4. Erk signaling regulates pyruvate metabolism. (A) MCF-10A cells treated with vehicle or $10 \mu M$ UO126 (UO) were cultured for $24 \mathrm{~h}$ in medium with $\left[1,2-{ }^{13} \mathrm{C}_{2}\right.$ ]glucose. Relative $\mathrm{PDH}$ flux was estimated by calculating the ratio of $\mathrm{M} 2$ metabolite labeling to that of pyruvate in triplicate, and average values are presented. (B) MCF-10A cells were plated as in $A$. Twenty-four hours later, the levels of pSer293 PDH were determined by immunofluorescence. Cells were scored as containing high or low levels of pSer293 PDH staining (colocalizing with the mitochondrial marker cytochrome c). Data are presented as an average of three independent experiments. $(C, D)$ MCF-10A ErbB2-attached (Att) or -detached (Detach) $(C)$ and MCF-10A-attached $(D)$ cells were treated with vehicle or $10 \mu M$ UO126 (UO), and pyruvate consumption was determined $24 \mathrm{~h}$ later. Data are presented as an average of three independent experiments. (E) MCF-10A-attached cells treated with vehicle or $10 \mu \mathrm{M}$ UO126 (UO) were cultured with $\left[1,2-{ }^{13} \mathrm{C}_{2}\right]$ glucose. The concentration of M1 and M2 pyruvate in the spent medium in triplicate was measured by GC/MS and used to assess pyruvate synthesis/secretion; average values are shown. $(F, G)$ MCF-10A ErbB2 $(F)$ and MCF-10A $(G)$ cells treated with vehicle or $10 \mu M$ UO126 (UO) were plated on control or polyHEMA plates for $24 \mathrm{~h}$. Changes in medium glucose and glutamine concentration were determined and normalized to vehicletreated attached cells. Data are presented as an average of more than three independent experiments. 
Grassian et al.

A
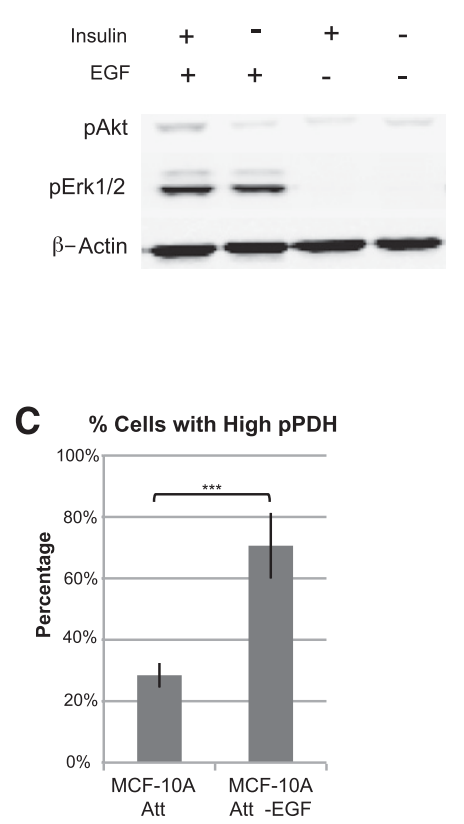

E
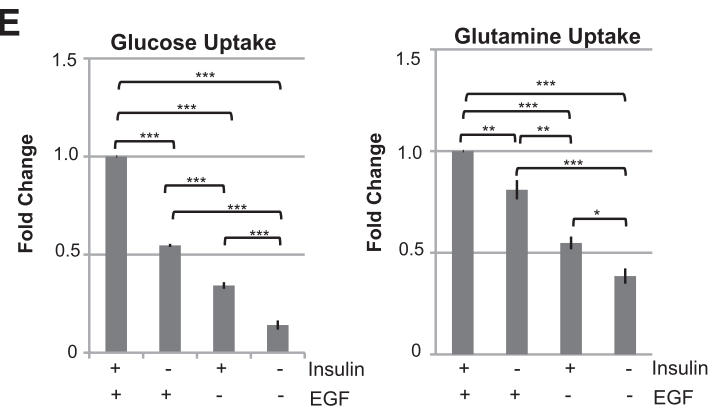

G

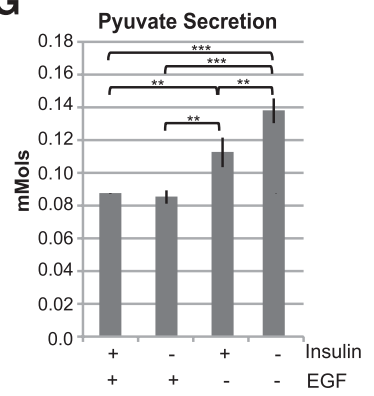

B
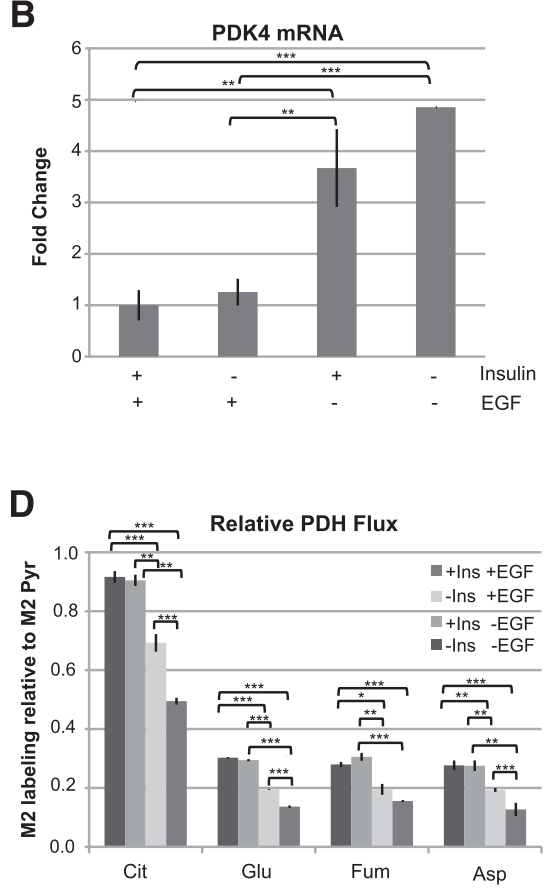

F

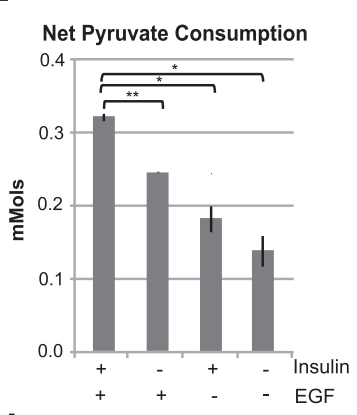

H

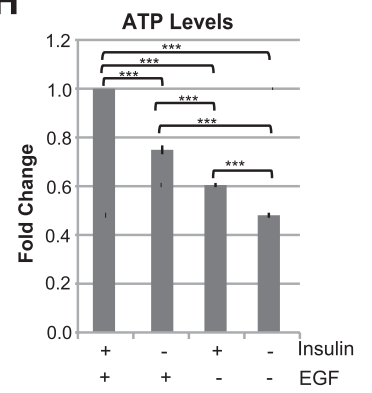

Figure 5. Differential regulation of PDK4, PDH flux, and nutrient uptake by insulin and EGF. $(A)$ MCF-10A cells were cultured in the presence $(+)$ or absence $(-)$ of insulin and EGF for $24 \mathrm{~h}$. Expression or phosphorylation of the indicated proteins was determined by immunoblotting. $(B)$ Cells were cultured as in $A$, and PDK4 mRNA levels were quantified by qPCR. Data are normalized to (+) EGF/ insulin conditions and are averages from three independent experiments. (C) MCF-10A cells were plated in the absence or presence of EGF. Twenty-four hours later, the levels of pSer293 PDH were determined by immunofluorescence. Cells were scored as containing high or low levels of pSer293 PDH staining colocalizing with the mitochondrial marker cytochrome c. Data are presented as an average of three independent experiments. $(D)$ Cells were cultured as in $A$ in the presence of $\left[1,2-{ }^{13} C_{2}\right]$ glucose. Relative PDH flux was estimated by calculating the ratio of $\mathrm{M} 2$ metabolite labeling to that of pyruvate in triplicate, and average values are presented. $(E)$ Cells were cultured as in $A$, and changes in medium levels of glucose and glutamine were determined. Data are normalized to (+) EGF/insulin conditions, and are averages of three independent experiments. $(F)$ Cells were cultured as in $A$. Changes in medium concentration of pyruvate were measured by GC/MS. Data represent averages from three independent experiments. $(G)$ Cells were cultured as in $D$. The concentration of M1 and M2 pyruvate in triplicate samples of spent medium was measured by GC/MS to assess pyruvate synthesis/ secretion, and average values are shown. $(H)$ Cells were cultured as in $A$, and $24 \mathrm{~h}$ later, ATP levels were measured using the ATPlite assay. Data are normalized to (+) EGF/insulin conditions, and are an average of three independent experiments. 
activation; PDK4 levels were high in the absence of EGF and insulin, suppressed in cells cultured in the presence of EGF, and insensitive to insulin (Fig. 5B). HMECs also displayed an increase in PDK4 levels in the absence of EGF (Supplemental Fig. S5B). In the MCF-10A cells, EGF withdrawal increased the phosphorylation of PDH (Fig. 5C; Supplemental Fig. S4A), correlating with the increased PDK4 levels.

We hypothesized that the differential regulation of PDK4 expression by EGF and insulin might translate to a specific role of EGF in controlling flux through PDH. Cells cultured in the absence of both insulin and EGF exhibited decreased relative PDH flux (Fig. 5D), consistent with the elevated PDK4 levels. Inclusion of insulin alone had a modest effect on pyruvate oxidation, whereas EGF alone increased relative PDH flux to the level observed in control cells cultured with both growth factors. Regulation of nutrient uptake by the two growth factors also correlated with differential activation of the downstream signaling pathways; removal of both insulin and EGF caused a considerable decrease in the net uptake of both glucose and glutamine (Fig. 5E). Insulin alone induced a small but noticeable increase in nutrient uptake, whereas EGF was much more effective. Maximal uptake of glucose and glutamine required both growth factors. As observed under conditions of ECM detachment and Mek inhibition, withdrawal of both EGF and insulin decreased net pyruvate consumption, due in part to higher pyruvate secretion (Fig. 5F,G). EGF alone was sufficient to suppress pyruvate secretion to the level observed with EGF and insulin. Similarly, alanine secretion increased with growth factor withdrawal; either growth factor alone decreased alanine secretion, although EGF alone was sufficient to maintain alanine secretion levels at the same levels as cells in full medium (Supplemental Fig. S5C).

Consistent with the changes in nutrient uptake and secretion, insulin and/or EGF withdrawal led to decreased ATP levels, with EGF withdrawal having a more prominent effect (Fig. 5H). Thus, EGF plays a more significant role than insulin in regulating flux of glucose and pyruvate-derived carbon into the TCA cycle, likely due to the stronger activation of Erk and the suppression of PDK4 expression.

\section{Regulation of PDH flux and ATP levels by PDK4}

As both ECM detachment, Mek inhibition, and EGF withdrawal increase PDK4 mRNA levels and decrease pyruvate oxidation, we examined how ectopic overexpression of PDK4 might modulate cellular metabolism in MCF10A and MCF-10A ErbB2 cells (Fig. 6A). Notably, we were unable to achieve equivalently high levels of PDK4 expression as either ECM detachment- or Mek inhibition-induced (fivefold vs. 30-fold) (see Figs. 3A,H, 6A; Supplemental Fig. $\mathrm{S} 3 \mathrm{G}, \mathrm{H}, \mathrm{J})$. Even with this moderate increase in PDK4 transcript levels, relative $\mathrm{PDH}$ flux was modestly, but significantly, decreased in the MCF-10A-attached and MCF-10A ErbB2-attached and -detached cells (Fig. 6B,C). The net change in medium pyruvate was also slightly decreased in cells overexpressing PDK4 (Fig. 6D,E); however, these changes were primarily caused by an increase in pyruvate secretion (Fig. 6F,G). PDK4 overexpression did not affect glucose or glutamine uptake or glutamate secretion (Supplemental Fig. S6A-C). Thus, PDK4 overexpression, similar to ECM detachment, Mek inhibition, and EGF withdrawal, decreases PDH flux and increases pyruvate secretion.

The maintenance of glucose uptake by ErbB2 is in part responsible for the rescue of ATP levels upon ECM detachment (Schafer et al. 2009). In addition, the suppression of PDK4 expression by ErbB2, which would maintain glucose entry into the TCA cycle, may also contribute to the maintenance of ATP levels. Overexpression of PDK4 in the MCF-10A cells did not increase the extent of ATP reduction caused by ECM detachment (Fig. 6H); this is not unexpected, given that PDK4 mRNA levels are induced 30-fold in MCF-10A ECM-detached cells. On the other hand, overexpression of PDK4 in the MCF-10A ErbB2 cells significantly impaired the rescue of ATP levels by ErbB2 after ECM detachment. Thus, PDK4 is a negative regulator of PDH flux, pyruvate consumption, and ATP production in MCF-10A cells.

\section{PDK4 overexpression decreases de novo lipogenesis and cell proliferation}

The TCA cycle is an important source of biosynthetic intermediates needed for cell proliferation. Indeed, glucose and pyruvate are important substrates that supply carbon to sustain de novo lipogenesis via PDH activity and the citrate shuttle. Cells cultured with either $\left[2-{ }^{13} \mathrm{C}\right]$ pyruvate or $\left[\mathrm{U}^{13}{ }^{13} \mathrm{C}_{6}\right]$ glucose for $4 \mathrm{~d}$ incorporated significant isotopic label into fatty acids. Pyruvate and glucose from the culture medium accounted for $\sim 17 \%$ and $65 \%$ of the carbon in newly synthesized fatty acids, respectively (Supplemental Fig. S7A). Importantly, ectopic expression of PDK4 caused a marked decrease in the level of de novo lipogenesis in both MCF-10A-attached and MCF-10A ErbB2-attached cells during this time, providing evidence that PDK4 inhibits the conversion of glucose and pyruvate to lipogenic AcCoA (Fig. 7A). Synthesis of fatty acids for membrane lipids is required for cell growth, and inhibition of fatty acid synthase (FASN) or reactions fueling this process can inhibit cell proliferation (Hatzivassiliou et al. 2005; DeBerardinis et al. 2008a; Vander Heiden et al. 2009; Wise and Thompson 2010). Consistent with the observed decrease in de novo lipogenesis, PDK4 overexpression led to a $40 \%-60 \%$ decrease in proliferation of MCF-10A-attached and MCF-10A ErbB2-attached cells after $4 \mathrm{~d}$ in culture (Fig. $7 \mathrm{~B}, \mathrm{C})$. PDK4 overexpression induced a slight increase in cell death as measured by trypan blue staining $(1 \%-3 \%)$ (Supplemental Fig. S7B); however, no increase in apoptotic cells was detected when assessed by sub-G1 DNA content (Fig. 7D,E). These results indicate that increased cell death is not likely to account for the $40 \%-60 \%$ decrease in cell numbers observed. Importantly, fewer cells were observed in the S and G2 phases of the cell cycle when PDK4 was overexpressed in the MCF-10A ErbB2 cells (Fig. 7D). MCF-10A cells displayed a similar trend, but the changes did not reach statistical significance (Fig. 7E). Thus, the suppression of PDK4 by Erk signaling, which is 

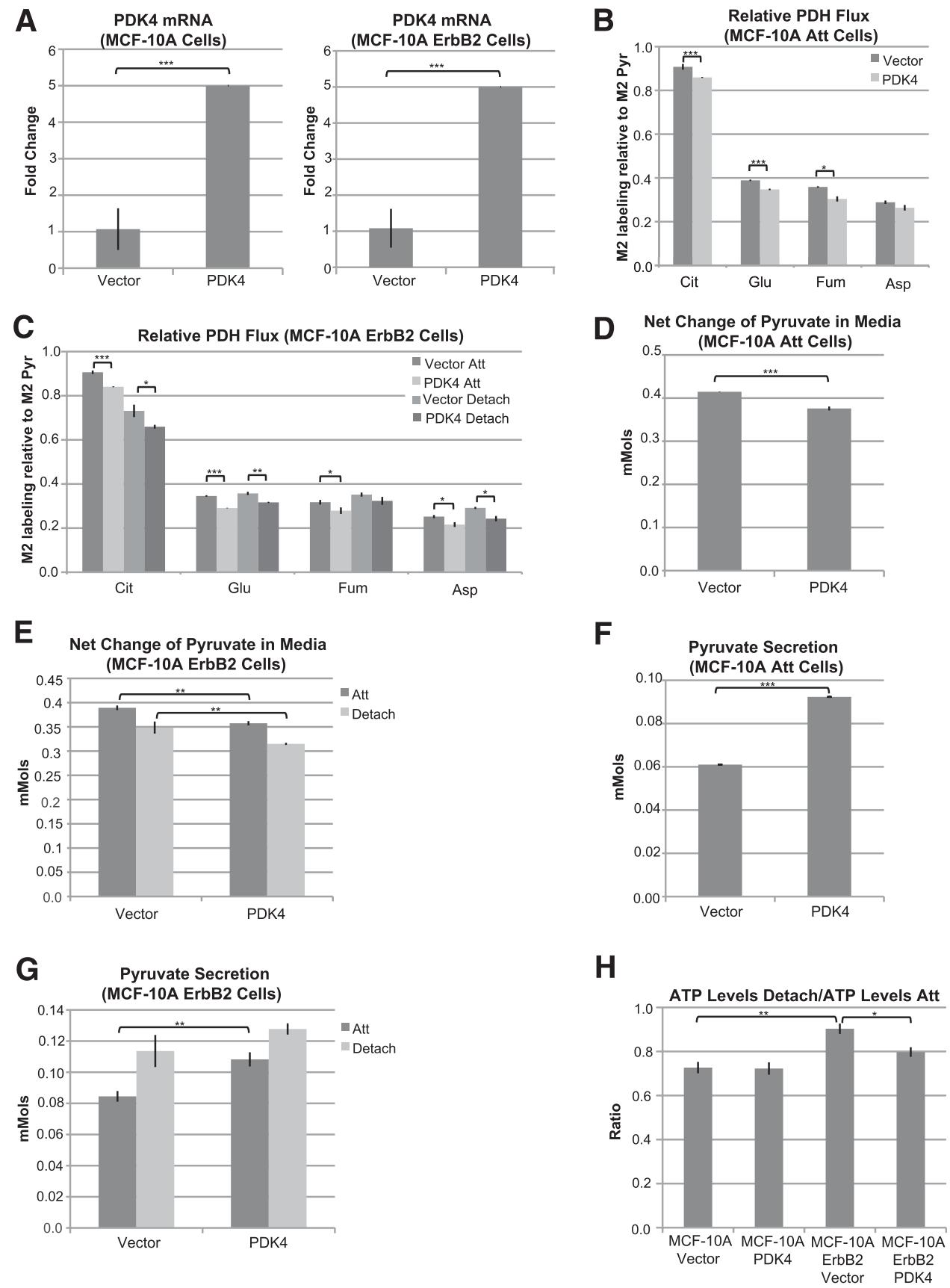

Figure 6. PDK4 regulates glucose entry into the TCA cycle and ATP levels. (A) mRNA levels of PDK4 in MCF-10A or MCF-10A ErbB2 cells infected with control pBABE-IRES-NEO vector (Vector) or pBABE-PDK4-IRES-NEO (PDK4) were quantified by qPCR. Data are normalized to vector control cells from each experiment, and are presented as averages from three independent experiments. (B,C) MCF-10A $(B)$ and MCF-10A ErbB2 $(C)$ cells infected with control vector or pBABE-PDK4-IRES-NEO were plated on control (Att) or polyHEMA-coated (Detach) plates for $24 \mathrm{~h}$ in medium containing $\left[1,2-{ }^{13} \mathrm{C}_{2}\right]$ glucose. Relative PDH flux was estimated by calculating the ratios of $\mathrm{M} 2 \mathrm{metabolite}$ labeling in triplicate, and average values are presented. $(D, E)$ Cells were plated as in $B$ and $C$, and pyruvate levels in spent medium were quantified by GC/MS. Data are presented as the average of three independent experiments. $(F, G)$ Cells were cultured as in $B$ and $C$. The concentration of $\mathrm{M} 1$ and $\mathrm{M} 2$ pyruvate in the spent medium was measured by GC/MS in triplicate and used to assess pyruvate secretion. $(H)$ MCF-10A and MCF-10A ErbB2 cells infected with control vector or pBABE-PDK4-IRES-NEO were plated on control (Att) or polyHEMAcoated (Detach) plates for $24 \mathrm{~h}$, and ATP levels were measured using the ATPlite assay. Data are presented as the ratio of ATP levels in detached cells to ATP levels in attached cells, and are the average of three independent experiments.

mediated by EGF stimulation, ErbB2, and ECM attachment, is important for maintaining high rates of cell proliferation.
We also evaluated whether PDK4 expression changes under conditions where cells undergo proliferation arrest. MCF-10A cells grown in three-dimensional (3D) culture 
A

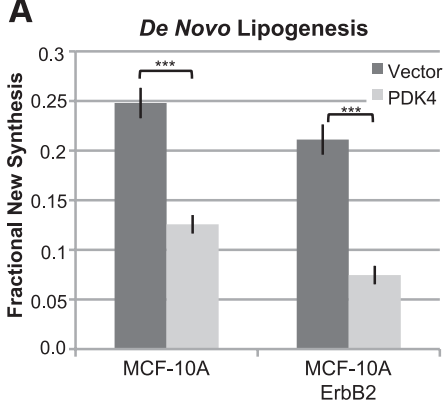

B

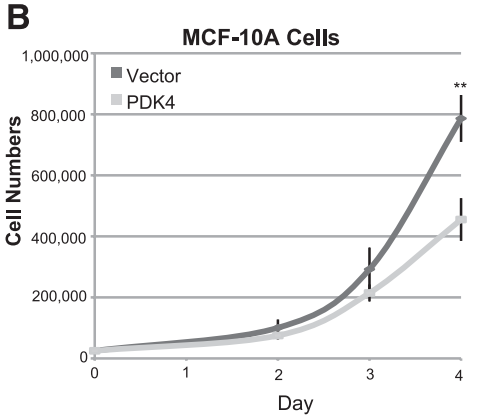

C

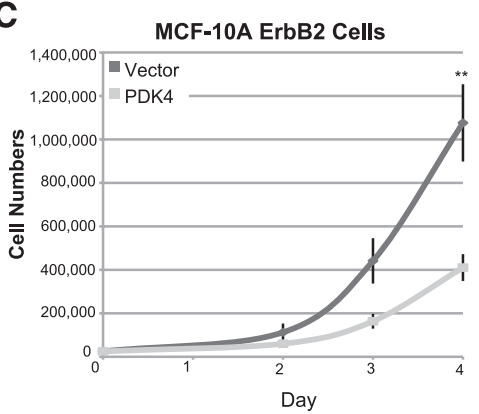

D

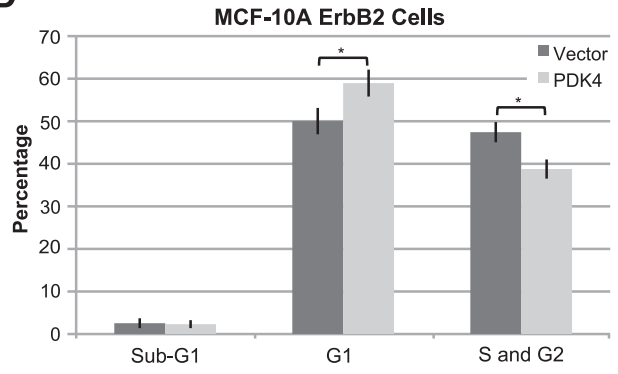

E

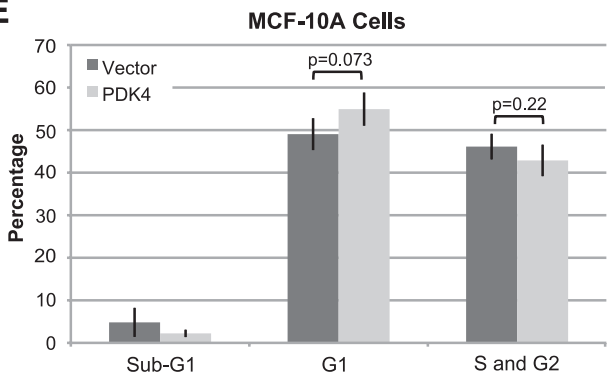

MCF-10A ErbB2 Cells
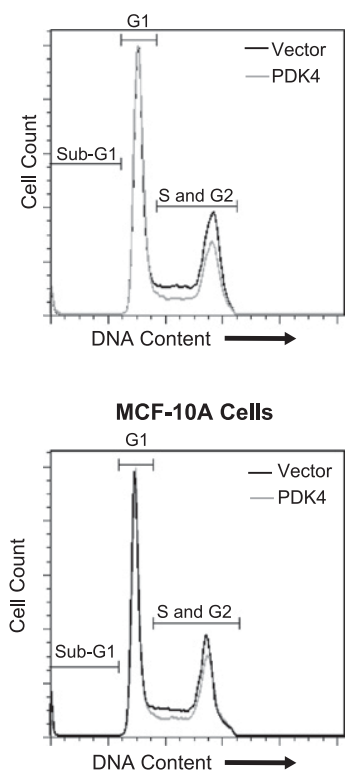

$\mathbf{F}$

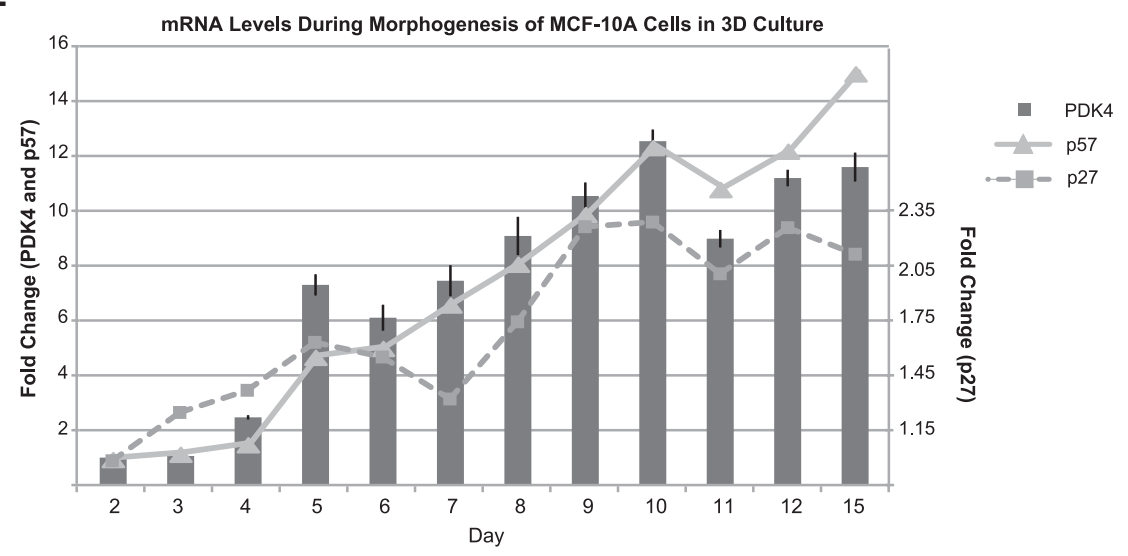

Figure 7. PDK4 negatively regulates de novo lipogenesis and cell proliferation. (A) MCF-10A or MCF10A ErbB2 cells infected with control vector (Vector) or pBABE-PDK4-IRES-NEO (PDK4) were cultured under attached conditions in the presence of [U- ${ }^{13} \mathrm{C}_{6}$ ] glucose or $\left[2-{ }^{13} \mathrm{C}\right]$ pyruvate. Medium was replaced every $24 \mathrm{~h}$. After $4 \mathrm{~d}$, the percentage of newly synthesized palmitate was determined via isotopomer spectral analysis (ISA). Palmitate-labeling data and complete ISA results are listed in Supplemental Table S2. Error bars indicate $95 \%$ confidence intervals. $(B, C)$ MCF-10A $(B)$ or MCF10A ErbB2 $(C)$ cells infected with control vector or pBABE-PDK4-IRESNEO were plated at equal concentration. After 2,3 or $4 \mathrm{~d}$, cell numbers were determined using a hemocytometer. $(D, E)$ MCF-10A ErbB2 $(D)$ or MCF10A $(E)$ cells infected with control vector or pBABE-PDK4-IRES-NEO were cultured under attached conditions. FACS analysis was performed to determine the percentage of cells in sub-G1, G1, and S/G2. (Left panels) Averages of data from three independent experiments. (Right panels) Representative histograms from one of three independent experiments. $(F)$ mRNA levels for PDK4, p27 (CDKN1B), and p57 (CDKN1C) were extracted from a data set derived from MCF-10A cells cultured in reconstituted basement membrane for $15 \mathrm{~d}$ (originally described in Schmelzle et al. 2007). Data represent the average fold change relative to the levels on day 2 from triplicate samples harvested at each of the indicated days. 
with EGF undergo an initial period of proliferation, before EGF signaling decreases and the cells undergo proliferation arrest (between day 5 and day 7) (Debnath et al. 2002; Schmelzle et al. 2007). We examined PDK4 expression in microarray data obtained from 3D cultures harvested throughout morphogenesis (Schmelzle et al. 2007) and found that expression of PDK4 increases at day 5, continues to increase to day 10, and then plateaus (Fig. 7F), correlating with expression of the two CDK inhibitors p27 and p57. Thus, in the 3D cell culture system, PDK4 expression correlates with growth arrest and expression of cell cycle inhibitors.

\section{Discussion}

Since the initial observation by Otto Warburg of high lactate production by tumor cells, much attention has been given to the process of aerobic glycolysis in proliferating cells (Warburg 1924; Vander Heiden et al. 2009; Fritz and Fajas 2010). However, there is a growing appreciation for the role of TCA metabolism in energy production, cofactor regeneration, and biosynthesis for cell growth in both tumors and nontransformed cells (Wise et al. 2008; Lemons et al. 2010; Weinberg et al. 2010; Cheng et al. 2011). As such, detailed knowledge describing how oncogenes, mitogens, and environmental factors coordinate flux through glycolysis and the TCA cycle will facilitate the exploitation of these metabolic changes to target neoplastic tissues.

Acquisition of anchorage independence is likely a key step in tumor progression. A deeper understanding of how ECM detachment affects cell viability and how oncogenes can reverse these changes may help to design targeted therapies for cancer treatment. In this study, we show that loss of ECM attachment results in decreased nutrient uptake in immortalized mammary epithelial cells and a consequent decrease in flux through glycolysis, the PPP, and the TCA cycle. In addition, detached cells display an increase in PDK4 levels, contributing to a disproportionate decrease in $\mathrm{PDH}$ flux that is independent of nutrient uptake (Fig. 8A). Ectopic expression of the ErbB2 oncogene rescues nutrient uptake and ATP levels after matrix detachment. Additionally, ErbB2 partially suppresses the induction of PDK4 upon matrix detachment in an Erkdependent manner and maintains PDH flux. In adherent cells, EGF-mediated activation of the Erk signaling pathway negatively regulates PDK4 mRNA and positively regulates $\mathrm{PDH}$ flux. The maintenance of low PDK4 levels and high PDH flux by ErbB2 in the ECM-detached cells may be important for its ability to prevent this metabolic defect, as overexpression of PDK4 compromises maintenance of ATP levels in the ECM-detached cells. Furthermore, PDK4 overexpression decreases de novo lipogenesis and cell proliferation in adherent cells, suggesting that changes in PDH flux may influence the rate of cell growth. Correlating with the suppression of proliferation and induction by matrix detachment, PDK4 levels are increased in growth-arrested 3D acinar structures. These results highlight the importance of $\mathrm{PDH}$ regulation in proliferating cells, as the conversion of glucose to AcCoA provides substrates for the production of ATP by oxidative phosphorylation and the production of intermediates for lipid, amino acid, and pyrimidine synthesis in the TCA cycle, and provide evidence that maintenance of PDH flux may be important for proliferation of tumor cells.

Decreased PDH flux under conditions of ECM detachment, Erk inhibition, EGF withdrawal or PDK4 overexpression likely contributes to the inhibition of cell proliferation we observed under these conditions. One possible mechanism by which the reduction in PDH flux could affect proliferation is through reduced de novo lipogenesis, as fatty acid synthesis is critical for the production of new membrane during cell growth and proliferation. Indeed, PDH flux has been previously shown to correlate with lipogenesis (Stansbie et al. 1976; Munday and Williamson 1981; Holness and Sugden 1990; Choi et al. 2010 ) and we observed a $50 \%-65 \%$ decrease in the relative level of de novo lipogenesis in our MCF-10A models. Glucose-derived carbons, metabolized by $\mathrm{PDH}$, are considered to be the primary source of AcCoA for lipogenesis in mammalian cells (Hatzivassiliou et al. 2005). While glutaminolysis provides another possible source of carbons for lipogenesis, we observed that glutamine is not a major source of carbons for lipogenesis in MCF-10A cells grown under normal culture conditions (CM Metallo and G Stephanopoulos, unpubl.), and glutamine is unable to compensate for the decrease in glucose flux to the TCA cycle in ECM-detached cells. Additionally, TCA intermediates are used for other biosynthetic reactions, including pyrimidine and amino acid synthesis (DeBerardinis et al. 2007, 2008a; Vander Heiden et al. 2009; Wise and Thompson 2010), and their supply may also be compromised due to decreased PDH flux. Furthermore, AcCoA production from the TCA cycle has recently been shown to be an important source of the acetyl groups used for histone acetylation (Wellen et al. 2009), placing PDH and PDK4 in a position to have global effects on gene expression that may regulate many cellular functions.

In contrast to our studies showing that PDK4 up-regulation decreases ATP levels and suppresses de novo lipogenesis and proliferation, recent work has highlighted the importance of $\mathrm{PDH}$ inhibition in driving tumorigenesis, as such regulation is expected to enhance aerobic glycolysis (Roche and Hiromasa 2007; DeBerardinis et al. 2008a; McFate et al. 2008; Michelakis et al. 2008; Vander Heiden et al. 2009; Sun et al. 2010). Indeed, studies have shown that pharmacological inhibition or decreased expression of PDKs can lead to decreased tumor growth in vivo (Bonnet et al. 2007; Roche and Hiromasa 2007; Michelakis et al. 2008). It is possible that $\mathrm{PDH}$ flux rates vary during different stages of tumor development depending on the extent to which distinct metabolic pathways are used for energy production and anabolic biosynthesis. PDK4 mRNA expression is significantly lower in a variety of human tumor types (including breast, ovarian, colon, and lung cancers) compared with their corresponding normal tissues in 35 studies available through Oncomine $(P$-values as low as $1.26 \times 10^{-18}$ ) (Fig. $8 \mathrm{~B}$ ). Importantly, not a single data set on Oncomine showed a statistically significant $(P<$ $\left.1 \times 10^{-4}\right)$ increase in PDK4 expression tumors relative to 

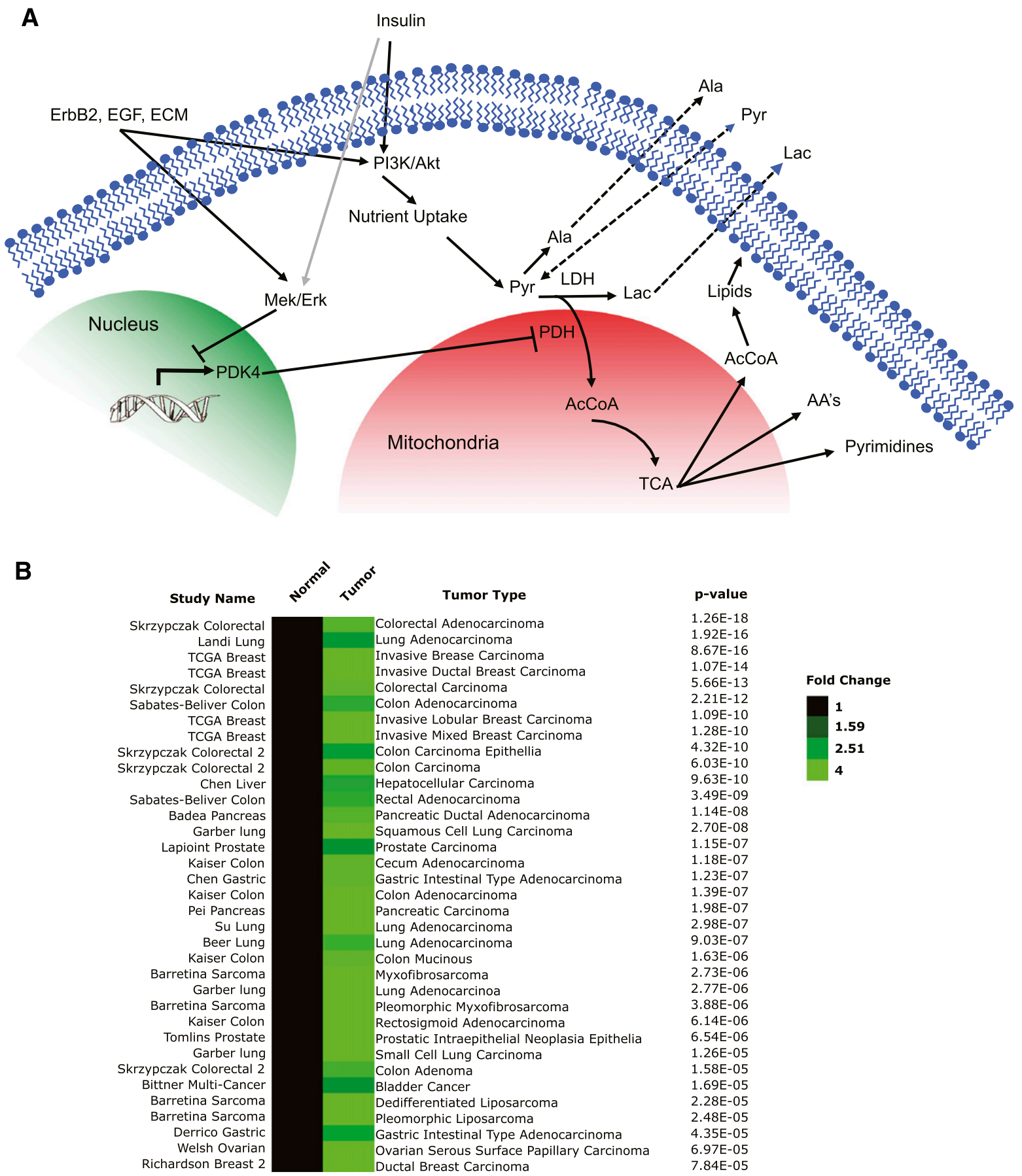

Figure 8. Overexpression of PDK4 suppresses cell proliferation. (A) In MCF-10A cells, PDK4 is a negative regulator of PDH flux. In attached cells plated in the presence of EGF, Erk activity maintains low levels of PDK4 transcription, allowing for entry of glucose carbons into the TCA cycle, and production of ATP and biosynthetic intermediates for lipid, nucleotide, and amino acid synthesis. In MCF-10Adetached cells or -attached cells starved of EGF, Erk activation is decreased, leading to high PDK4 levels, low PDH flux, and increased secretion of lactate, pyruvate, and alanine (dashed arrow). This contributes to the decreases in ATP and proliferation. Ectopic expression of ErbB2, in an Erk-dependent manner, partially prevents the increase in PDK4 levels in the ECM-detached cells, and thus maintains PDH flux and ATP levels. Overexpression of PDK4 decreases PDH flux, leading to a decrease in production of ATP and biosynthetic intermediates from the TCA cycle, which results in decreased de novo lipogenesis and proliferation. The PI3K/Akt pathway regulates nutrient (glucose, glutamine, and pyruvate) uptake. The gray arrow indicates weak activation of Erk by insulin. (AAs) Amino acids; (Ala) alanine; (Cyt) cytoplasm; (Lac) lactate; (Mit) mitochondria; (Nuc) nucleus; (Pyr) pyruvate. (B) Heat map of fold change in PDK4 expression in tumor samples. Data are publicly available on Oncomine, and citations are included as Supplemental Material. 
the corresponding normal tissue. These studies are consistent with our results indicating that PDK4 up-regulation has a suppressive effect on proliferation.

Our findings regarding the regulation of proliferation by PDK4 and the changes in PDK4 expression in tumors suggests that $\mathrm{PDH}$ flux is important for growth of tumor cells. Although many tumor cells do display an increase in the ratio of lactate produced to glucose taken up (the Warburg effect), there is not a complete suppression of PDH flux (DeBerardinis 2008). The TCA cycle supplies intermediates for lipid, nucleotide, and amino acid synthesis that are critical for cell proliferation, and the oxidation of pyruvate to AcCoA (via PDH) is important for maintenance of TCA cycle flux. PDKs likely act as a sensor of nutrient and oxygen availability, and thus regulate the usage of intermediates for distinct metabolic needs under different conditions, thereby regulating proliferation rates. Aberrant PDK4 expression would therefore lead to inappropriate diversion of carbons away from the TCA cycle and decreased proliferation.

Our results also highlight key specificities in different growth factor signaling pathways, as we demonstrate a specific role of Mek/Erk signaling in suppressing PDK4 expression, whereas inhibition of $\mathrm{PI} 3 \mathrm{~K} / \mathrm{m}$ Tor does not affect PDK4 levels. Additional studies are required to elucidate the specific mechanism through which Erk regulates PDK4 mRNA, the levels of which have been shown to be controlled by numerous proteins and signaling pathways (Abbot et al. 2005; Sugden and Holness 2006; Roche and Hiromasa 2007). Some transcriptional regulators of PDK4, such as retinoid X receptor and FOXO1, have previously been found to be negatively regulated by Erk signaling (Arnaud et al. 2004; Coll et al. 2006; Asada et al. 2007; Burgermeister et al. 2007; Macoritto et al. 2008; Shankar et al. 2008; Meng et al. 2011). Importantly, previous studies implicating PI3K/Akt as a negative regulator of PDK4 expression were performed in myocytes (Puthanveetil et al. 2010), which must generate significant energy (i.e., ATP) from glucose in response to insulin to function properly (Latronico et al. 2004). Thus, PDK4 may be regulated in a tissue-specific manner in order to respond to a variety of stimuli and induce the appropriate changes in metabolic flux. Similarly, we observed different roles for Mek/Erk and PI3K/Akt signaling in the regulation of nutrient uptake and intracellular metabolism; these findings underscore the importance of coordinated regulation of cellular metabolism by integration of signals from multiple pathways. Since PDK4 expression is regulated by distinct pathways in other cell types, these results also highlight cell type differences in control of this key metabolic enzyme. In addition, these results suggest potential differential dependencies on PDH flux between normal and transformed cells. While PDK4 overexpression displayed a similar suppression of $\mathrm{PDH}$ flux in control and ErbB2-overexpressing MCF-10A cells, the control cells displayed a lower dependence on PDH flux for de novo lipogenesis and proliferation than do the ErbB2-overexpressing cells $150 \%$ vs. $65 \%$ decrease in lipogenesis, and $40 \%$ vs. $60 \%$ decrease in cell number).
In summary, while the studies reported here were initially focused on defining the metabolic pathways regulated by matrix attachment, findings from these investigations provided important insights relating more broadly to the regulation of glucose metabolism. We describe novel aspects of signaling pathway control of metabolic flux that in turn regulate other cellular process such as cell proliferation. It is likely that such fine controls of metabolic activity, like those reported here and in other recent studies of oncogene-expressing cells (Bensaad et al. 2006; Fantin et al. 2006; Wise et al. 2008), escaped detection in earlier studies that were generally focused on cell types involved in physiological metabolism of nutrients, such as hepatocytes, adipocytes, and muscle cells, or in established tumor cells. As interest in the metabolism of transformed cells increases, more metabolic distinctions between normal and oncogene-transformed cells, such as the differential dependence on PDH flux identified here, are likely to emerge.

\section{Materials and methods}

\section{Cell culture}

MCF-10A cells were cultured as described previously (Debnath et al. 2003; http://brugge.med.harvard.edu). NMuMG cells, HMECs, and HC11 cells were cultured as previously described (Brandt et al. 2001; Overholtzer et al. 2006; Ursini-Siegel et al. 2007).

\section{Metabolite extraction and GC/MS analysis}

Cell culture, metabolite extraction and derivatization, model description, analysis, and assumptions are described in detail in the Supplemental Material. Briefly, metabolites were extracted at the end of culture using equal volumes of methanol, water, and chloroform before evaporation under airflow. For polar metabolites, derivatization was accomplished by dissolving evaporated aqueous fraction with $2 \%$ methoxamine hydrochloride in pyridine and incubating for $90 \mathrm{~min}$ at $37^{\circ} \mathrm{C}$, followed by either tert-butyldimethylsilylation using N-methyl-N-(tert-butyldimethylsilyl)trifluoroacetamide (MBTSTFA) + 1\% tert-butyldimethylchlorosilane (TBDMCS) (Pierce) or trimethylsilylation using 2,2,2-trifluoro$\mathrm{N}$-methyl-N-trimethylsilyl-acetamide (MSTFA) $+1 \%$ trimethylchlorosilane (TMCS) (Pierce). Fatty acid methyl esters were generated using the Methyl-8 reagent (Pierce). The GC/MS was operated as previously described (Metallo et al. 2009). Ion fragments integrated for metabolite and isotope quantification are listed in the Supplemental Material. Labeling of metabolites was corrected for natural isotope abundances using an in-house algorithm adapted from Fernandez et al. (1996). MFA and isotopomer spectral analysis (ISA) calculations were performed using Metran, an algorithm for flux and confidence interval determination (Young et al. 2008).

\section{Metabolite analysis of spent medium}

Metabolite levels in the medium were measured using the Yellow Springs Instruments (YSI) 7100 or by GC/MS as described in the Supplemental Material.

\section{Analysis of $m R N A$ expression}

qPCR was performed as previously described (Grassian et al. 2011) and as in the Supplemental Material. Microarray analyses 
on MCF-10A cells during morphogenesis were performed as described previously (Schmelzle et al. 2007).

\section{Immunoblotting}

Cells were lysed and analyzed by immunoblotting as previously described (Grassian et al. 2011) and as in the Supplemental Material.

\section{Quantification of pPDH levels}

Cells were fixed in $4 \%$ paraformaldehyde (Electron Microscopy Sciences) and permeabilized with $0.1 \%$ Triton X-100 (Sigma), followed by staining with anti-cytochrome c (BD Biosciences) and/or anti-pPDH S293 (Novus) primary antibodies and Alexa Fluor 488 and/or 568 secondary antibodies (Invitrogen). For immunofluorescence, $>100$ cells from 10 fields per condition from three independent experiments were blindly scored for high mitochondrial (colocalizing with cytochrome c) pPDH staining. Images were acquired using a $40 \times$ objective. For flow cytometry, at least 25,000 counts from three independent experiments were acquired on a FACSCalibur flow cytometer (BD Biosciences) and analyzed with FlowJo software (Treestar).

\section{ATP assay}

ATP levels were determined using the ATPlite assay (Perkin Elmer) as previously described (Grassian et al. 2011) and as in the Supplemental Material.

\section{Cell proliferation assay}

To quantify cell proliferation, 25,000 MCF-10A or MCF-10A ErbB2 cells infected with a control vector or PDK4 overexpression vector were plated. Two days, $3 \mathrm{~d}$, or $4 \mathrm{~d}$ later, cells were counted using a hemocytometer.

\section{Cell death analysis and cell cycle analysis}

Analysis of cell death was performed using Trypan blue exclusion and cell cycle analysis by flow cytometry. Detailed methods are described in the Supplemental Material.

\section{Oncomine data mining}

Normalized PDK4 expression data and $P$-values were downloaded from Oncomine (Compendia Bioscience). Citations for individual studies are included as the Supplemental Material. Heat maps were generated using Cluster 3.0 and Java TreeView 1.1.1.

\section{Statistics}

All results shown as averages are presented as mean \pm SE. $P$-values were calculated using a Student's two-tailed $t$-test: $\left({ }^{\star}\right)$ $P$-value between 0.01 and $0.05 ;\left(^{\star \star}\right) P$-value between 0.001 and $0.01 ;\left(^{\star \star \star}\right) P$-value $<0.001$. All errors associated with MFA and ISA of lipogenesis are $95 \%$ confidence intervals determined via sensitivity analysis.

\section{Acknowledgments}

We thank Devin Worster and Drs. John Albeck, Lewis Cantley, Nika Danial, Ralph DeBerardinis, Lisa Gallegos, Joanne Kelleher, Ghassan Mouneimne, Zachary Schafer, Laura Selfors, Shomit Sengupta, and Bruce Zetter for helpful discussions of this work and/or experimental assistance. We thank Dr. William Muller for providing us with his NMuMG series of cell lines. We thank Drs. Tobias Schmelze, Nicole Solimini, and Eric Lightcap and his colleagues at Millennium for performing the microarray analyses of 3D, attached, and detached MCF-10A cells. This work was supported by grant CA105134 from the National Cancer Institute (to J.S.B.). A.R.G. is a recipient of a National Science Foundation Graduate Research Fellowship. C.M.M is supported by a postdoctoral fellowship from the American Cancer Society.

\section{References}

Abbot EL, McCormack JG, Reynet C, Hassall DG, Buchan KW, Yeaman SJ. 2005. Diverging regulation of pyruvate dehydrogenase kinase isoform gene expression in cultured human muscle cells. FEBS J 272: 3004-3014.

Antoniewicz MR, Kelleher JK, Stephanopoulos G. 2006. Determination of confidence intervals of metabolic fluxes estimated from stable isotope measurements. Metab Eng 8: 324-337.

Arnaud M, Crouin C, Deon C, Loyaux D, Bertoglio J. 2004. Phosphorylation of Grb2-associated binder 2 on serine 623 by ERK MAPK regulates its association with the phosphatase SHP-2 and decreases STAT5 activation. I Immunol 173: 39623971.

Asada S, Daitoku H, Matsuzaki H, Saito T, Sudo T, Mukai H, Iwashita S, Kako K, Kishi T, Kasuya Y, et al. 2007. Mitogenactivated protein kinases, Erk and p38, phosphorylate and regulate Foxo1. Cell Signal 19: 519-527.

Bensaad K, Tsuruta A, Selak MA, Vidal MN, Nakano K, Bartrons R, Gottlieb E, Vousden KH. 2006. TIGAR, a p53-inducible regulator of glycolysis and apoptosis. Cell 126: 107-120.

Bonnet S, Archer SL, Allalunis-Turner J, Haromy A, Beaulieu C, Thompson R, Lee CT, Lopaschuk GD, Puttagunta L, Harry $\mathrm{G}$, et al. 2007. A mitochondria-K+ channel axis is suppressed in cancer and its normalization promotes apoptosis and inhibits cancer growth. Cancer Cell 11: 37-51.

Boros LG, Brackett DJ, Harrigan GG. 2003. Metabolic biomarker and kinase drug target discovery in cancer using stable isotope-based dynamic metabolic profiling (SIDMAP). Curr Cancer Drug Targets 3: 445-453.

Brandt R, Wong AM, Hynes NE. 2001. Mammary glands reconstituted with $\mathrm{Neu} / \mathrm{ErbB} 2$ transformed $\mathrm{HC} 11$ cells provide a novel orthotopic tumor model for testing anti-cancer agents. Oncogene 20: 5459-5465.

Burgermeister E, Chuderland D, Hanoch T, Meyer M, Liscovitch M, Seger R. 2007. Interaction with MEK causes nuclear export and downregulation of peroxisome proliferator-activated receptor $\gamma$. Mol Cell Biol 27: 803-817.

Cheng T, Sudderth J, Yang C, Mullen AR, Jin ES, Mates JM, DeBerardinis RJ. 2011. Pyruvate carboxylase is required for glutamine-independent growth of tumor cells. Proc Natl Acad Sci 108: 8674-8679.

Chiarugi P, Giannoni E. 2008. Anoikis: a necessary death program for anchorage-dependent cells. Biochem Pharmacol 76: 1352-1364.

Choi CS, Ghoshal P, Srinivasan M, Kim S, Cline G, Patel MS. 2010. Liver-specific pyruvate dehydrogenase complex deficiency upregulates lipogenesis in adipose tissue and improves peripheral insulin sensitivity. Lipids 45: 987-995.

Coll T, Jove M, Rodriguez-Calvo R, Eyre E, Palomer X, Sanchez RM, Merlos M, Laguna JC, Vazquez-Carrera M. 2006. Palmitate-mediated downregulation of peroxisome proliferatoractivated receptor- $\gamma$ coactivator $1 \alpha$ in skeletal muscle cells involves MEK1/2 and nuclear factor-кB activation. Diabetes 55: $2779-2787$. 
DeBerardinis RJ. 2008. Is cancer a disease of abnormal cellular metabolism? New angles on an old idea. Genet Med 10: 767777.

DeBerardinis RJ, Mancuso A, Daikhin E, Nissim I, Yudkoff M, Wehrli S, Thompson CB. 2007. Beyond aerobic glycolysis: transformed cells can engage in glutamine metabolism that exceeds the requirement for protein and nucleotide synthesis. Proc Natl Acad Sci 104: 19345-19350.

DeBerardinis RJ, Lum JJ, Hatzivassiliou G, Thompson CB. 2008a. The biology of cancer: metabolic reprogramming fuels cell growth and proliferation. Cell Metab 7: 11-20.

DeBerardinis RJ, Sayed N, Ditsworth D, Thompson CB. 2008b. Brick by brick: metabolism and tumor cell growth. Curr Opin Genet Dev 18: 54-61.

Debnath J, Mills KR, Collins NL, Reginato MJ, Muthuswamy SK, Brugge JS. 2002. The role of apoptosis in creating and maintaining luminal space within normal and oncogeneexpressing mammary acini. Cell 111: 29-40.

Debnath J, Muthuswamy SK, Brugge JS. 2003. Morphogenesis and oncogenesis of MCF-10A mammary epithelial acini grown in three-dimensional basement membrane cultures. Methods 30: 256-268.

Edinger AL, Thompson CB. 2002. Akt maintains cell size and survival by increasing mTOR-dependent nutrient uptake. Mol Biol Cell 13: 2276-2288.

Fantin VR, St-Pierre J, Leder P. 2006. Attenuation of LDH-A expression uncovers a link between glycolysis, mitochondrial physiology, and tumor maintenance. Cancer Cell 9: 425-434.

Fernandez CA, Des Rosiers C, Previs SF, David F, Brunengraber H. 1996. Correction of 13C mass isotopomer distributions for natural stable isotope abundance. I Mass Spectrom 31: $255-262$.

Frisch SM, Screaton RA. 2001. Anoikis mechanisms. Curr Opin Cell Biol 13: 555-562.

Fritz V, Fajas L. 2010. Metabolism and proliferation share common regulatory pathways in cancer cells. Oncogene 29: 4369-4377.

Grassian AR, Schafer ZT, Brugge JS. 2011. ErbB2 stabilizes epidermal growth factor receptor (EGFR) expression via Erk and Sprouty2 in extracellular matrix-detached cells. I Biol Chem 286: 79-90.

Hanahan D, Weinberg RA. 2011. Hallmarks of cancer: the next generation. Cell 144: 646-674.

Hatzivassiliou G, Zhao F, Bauer DE, Andreadis C, Shaw AN, Dhanak D, Hingorani SR, Tuveson DA, Thompson CB. 2005. ATP citrate lyase inhibition can suppress tumor cell growth. Cancer Cell 8: 311-321.

Holness MJ, Sugden MC. 1990. Pyruvate dehydrogenase activities and rates of lipogenesis during the fed-to-starved transition in liver and brown adipose tissue of the rat. Biochem J 268: 77-81.

Horbinski C, Mojesky C, Kyprianou N. 2010. Live free or die. Tales of homeless (cells) in cancer. Am J Pathol 177: 10441052.

Hynes NE, Lane HA. 2005. ERBB receptors and cancer: the complexity of targeted inhibitors. Nat Rev Cancer 5: 341-354.

Kim JW, Tchernyshyov I, Semenza GL, Dang CV. 2006. HIF1-mediated expression of pyruvate dehydrogenase kinase: a metabolic switch required for cellular adaptation to hypoxia. Cell Metab 3: 177-185.

Latronico MV, Costinean S, Lavitrano ML, Peschle C, Condorelli G. 2004. Regulation of cell size and contractile function by AKT in cardiomyocytes. Ann NY Acad Sci 1015: 250-260.

Lazar DF, Wiese RJ, Brady MJ, Mastick CC, Waters SB, Yamauchi K, Pessin JE, Cuatrecasas P, Saltiel AR. 1995. Mitogen- activated protein kinase kinase inhibition does not block the stimulation of glucose utilization by insulin. I Biol Chem 270: 20801-20807.

Lemons JM, Feng XJ, Bennett BD, Legesse-Miller A, Johnson EL, Raitman I, Pollina EA, Rabitz HA, Rabinowitz JD, Coller HA. 2010. Quiescent fibroblasts exhibit high metabolic activity. PLOS Biol 8: e1000514. doi: 10.1371/journal.pbio. 1000514

Macoritto M, Nguyen-Yamamoto L, Huang DC, Samuel S, Yang XF, Wang TT, White JH, Kremer R. 2008. Phosphorylation of the human retinoid $\mathrm{X}$ receptor $\alpha$ at serine 260 impairs coactivator(s) recruitment and induces hormone resistance to multiple ligands. J Biol Chem 283: 4943-4956.

Macpherson I, Montagnier L. 1964. Agar suspension culture for the selective assay of cells transformed by polyoma virus. Virology 23: 291-294.

Mailleux AA, Overholtzer M, Schmelzle T, Bouillet P, Strasser A, Brugge JS. 2007. BIM regulates apoptosis during mammary ductal morphogenesis, and its absence reveals alternative cell death mechanisms. Dev Cell 12: 221-234.

McFate T, Mohyeldin A, Lu H, Thakar J, Henriques J, Halim ND, Wu H, Schell MJ, Tsang TM, Teahan O, et al. 2008. Pyruvate dehydrogenase complex activity controls metabolic and malignant phenotype in cancer cells. I Biol Chem 283: 22700-22708

Meng R, Pei Z, Zhang A, Zhou Y, Cai X, Chen B, Liu G, Mai W, Wei J, Dong Y. 2011. AMPK activation enhances PPAR $\alpha$ activity to inhibit cardiac hypertrophy via ERK1/2 MAPK signaling pathway. Arch Biochem Biophys 511: 1-7.

Metallo CM, Walther JL, Stephanopoulos G. 2009. Evaluation of 13C isotopic tracers for metabolic flux analysis in mammalian cells. J Biotechnol 144: 167-174.

Michelakis ED, Webster L, Mackey JR. 2008. Dichloroacetate (DCA) as a potential metabolic-targeting therapy for cancer. Br I Cancer 99: 989-994.

Mody N, Leitch J, Armstrong C, Dixon J, Cohen P. 2001. Effects of MAP kinase cascade inhibitors on the MKK5/ERK5 pathway. FEBS Lett 502: 21-24.

Munday MR, Williamson DH. 1981. Role of pyruvate dehydrogenase and insulin in the regulation of lipogenesis in the lactating mammary gland of the rat during the starved-refed transition. Biochem J 196: 831-837.

Munger J, Bennett BD, Parikh A, Feng XJ, McArdle J, Rabitz HA, Shenk T, Rabinowitz JD. 2008. Systems-level metabolic flux profiling identifies fatty acid synthesis as a target for antiviral therapy. Nat Biotechnol 26: 1179-1186.

Overholtzer M, Zhang J, Smolen GA, Muir B, Li W, Sgroi DC, Deng CX, Brugge JS, Haber DA. 2006. Transforming properties of YAP, a candidate oncogene on the chromosome 11q22 amplicon. Proc Natl Acad Sci 103: 12405-12410.

Papandreou I, Cairns RA, Fontana L, Lim AL, Denko NC. 2006. HIF-1 mediates adaptation to hypoxia by actively downregulating mitochondrial oxygen consumption. Cell Metab 3: 187-197.

Plas DR, Talapatra S, Edinger AL, Rathmell JC, Thompson CB. 2001. Akt and Bcl-xL promote growth factor-independent survival through distinct effects on mitochondrial physiology. I Biol Chem 276: 12041-12048.

Puthanveetil P, Wang Y, Wang F, Kim MS, Abrahani A, Rodrigues B. 2010. The increase in cardiac pyruvate dehydrogenase kinase-4 after short-term dexamethasone is controlled by an Akt-p38-forkhead box other factor-1 signaling axis. Endocrinology 151: 2306-2318.

Rardin MJ, Wiley SE, Naviaux RK, Murphy AN, Dixon JE. 2009. Monitoring phosphorylation of the pyruvate dehydrogenase complex. Anal Biochem 389: 157-164. 
Rathmell JC, Fox CJ, Plas DR, Hammerman PS, Cinalli RM, Thompson CB. 2003. Akt-directed glucose metabolism can prevent Bax conformation change and promote growth factor-independent survival. Mol Cell Biol 23: 7315-7328.

Reginato MJ, Mills KR, Paulus JK, Lynch DK, Sgroi DC, Debnath J, Muthuswamy SK, Brugge JS. 2003. Integrins and EGFR coordinately regulate the pro-apoptotic protein Bim to prevent anoikis. Nat Cell Biol 5: 733-740.

Roche TE, Hiromasa Y. 2007. Pyruvate dehydrogenase kinase regulatory mechanisms and inhibition in treating diabetes, heart ischemia, and cancer. Cell Mol Life Sci 64: 830-849.

Schafer ZT, Grassian AR, Song L, Jiang Z, Gerhart-Hines Z, Irie HY, Gao S, Puigserver P, Brugge JS. 2009. Antioxidant and oncogene rescue of metabolic defects caused by loss of matrix attachment. Nature 461: 109-113.

Schmelzle T, Mailleux AA, Overholtzer M, Carroll JS, Solimini NL, Lightcap ES, Veiby OP, Brugge JS. 2007. Functional role and oncogene-regulated expression of the BH3-only factor Bmf in mammary epithelial anoikis and morphogenesis. Proc Natl Acad Sci 104: 3787-3792.

Shankar S, Chen Q, Srivastava RK. 2008. Inhibition of PI3K/ AKT and MEK/ERK pathways act synergistically to enhance antiangiogenic effects of EGCG through activation of FOXO transcription factor. J Mol Signal 3: 7.

Stansbie D, Brownsey RW, Crettaz M, Denton RM. 1976. Acute effects in vivo of anti-insulin serum on rates of fatty acid synthesis and activities of acetyl-coenzyme A carboxylase and pyruvate dehydrogenase in liver and epididymal adipose tissue of fed rats. Biochem I 160: 413-416.

Sugden MC, Holness MJ. 2006. Mechanisms underlying regulation of the expression and activities of the mammalian pyruvate dehydrogenase kinases. Arch Physiol Biochem 112: 139-149.

Sugden MC, Fryer LG, Orfali KA, Priestman DA, Donald E, Holness MJ. 1998. Studies of the long-term regulation of hepatic pyruvate dehydrogenase kinase. Biochem J 329: 89-94.

Sugden MC, Holness MJ, Donald E, Lall H. 1999. Substrate interactions in the short- and long-term regulation of renal glucose oxidation. Metabolism 48: 707-715.

Sun RC, Fadia M, Dahlstrom JE, Parish CR, Board PG, Blackburn AC. 2010. Reversal of the glycolytic phenotype by dichloroacetate inhibits metastatic breast cancer cell growth in vitro and in vivo. Breast Cancer Res Treat 120: 253-260.

Ursini-Siegel J, Rajput AB, Lu H, Sanguin-Gendreau V, Zuo D, Papavasiliou V, Lavoie C, Turpin J, Cianflone K, Huntsman DG, et al. 2007. Elevated expression of DecR1 impairs ErbB2/ Neu-induced mammary tumor development. Mol Cell Biol 27: 6361-6371.

Vander Heiden MG, Cantley LC, Thompson CB. 2009. Understanding the Warburg effect: the metabolic requirements of cell proliferation. Science 324: 1029-1033.

Warburg EG. 1924. Über Wärmeleitung und andere ausgleichende Vorgänge. Springer, Berlin.

Weinberg F, Hamanaka R, Wheaton WW, Weinberg S, Joseph J, Lopez M, Kalyanaraman B, Mutlu GM, Budinger GR, Chandel NS. 2010. Mitochondrial metabolism and ROS generation are essential for Kras-mediated tumorigenicity. Proc Natl Acad Sci 107: 8788-8793.

Wellen KE, Thompson CB. 2010. Cellular metabolic stress: considering how cells respond to nutrient excess. Mol Cell 40: 323-332.

Wellen KE, Hatzivassiliou G, Sachdeva UM, Bui TV, Cross JR, Thompson CB. 2009. ATP-citrate lyase links cellular metabolism to histone acetylation. Science 324: 1076-1080.

Wellen KE, Lu C, Mancuso A, Lemons JM, Ryczko M, Dennis JW, Rabinowitz JD, Coller HA, Thompson CB. 2010. The hexosamine biosynthetic pathway couples growth factorinduced glutamine uptake to glucose metabolism. Genes Dev 24: 2784-2799.

Wise DR, Thompson CB. 2010. Glutamine addiction: a new therapeutic target in cancer. Trends Biochem Sci 35: 427-433.

Wise DR, DeBerardinis RJ, Mancuso A, Sayed N, Zhang XY, Pfeiffer HK, Nissim I, Daikhin E, Yudkoff M, McMahon SB, et al. 2008. Myc regulates a transcriptional program that stimulates mitochondrial glutaminolysis and leads to glutamine addiction. Proc Natl Acad Sci 105: 18782-18787.

Wu P, Blair PV, Sato J, Jaskiewicz J, Popov KM, Harris RA. 2000. Starvation increases the amount of pyruvate dehydrogenase kinase in several mammalian tissues. Arch Biochem Biophys 381: 1-7.

Young JD, Walther JL, Antoniewicz MR, Yoo H, Stephanopoulos G. 2008. An elementary metabolite unit (EMU) based method of isotopically nonstationary flux analysis. Biotechnol Bioeng 99: 686-699.

Zamboni N. 2011. (13)C metabolic flux analysis in complex systems. Curr Opin Biotechnol 22: 103-108. 


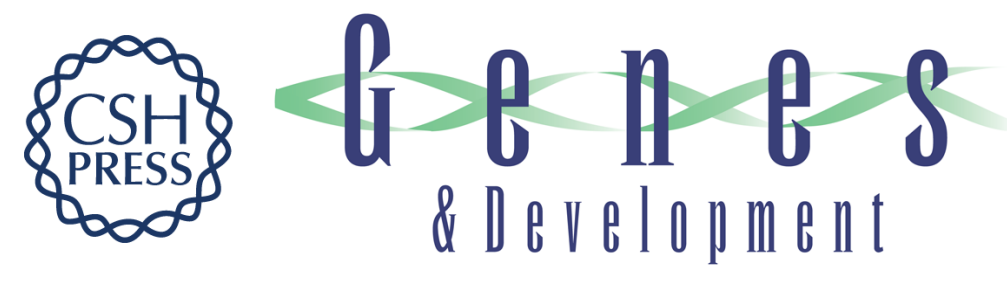

\section{Erk regulation of pyruvate dehydrogenase flux through PDK4 modulates cell proliferation}

Alexandra R. Grassian, Christian M. Metallo, Jonathan L. Coloff, et al.

Genes Dev. 2011, 25:

Access the most recent version at doi:10.1101/gad.16771811

\section{Supplemental http://genesdev.cshlp.org/content/suppl/2011/08/18/25.16.1716.DC1 Material}

Related Content Removing a Metabolic Roadblock

Annalisa M. VanHook

Sci. Signal. August, 2011 4: ec240

References This article cites 71 articles, 23 of which can be accessed free at: http://genesdev.cshlp.org/content/25/16/1716.full.html\#ref-list-1

Articles cited in:

http://genesdev.cshlp.org/content/25/16/1716.full.html\#related-urls

\section{License}

Email Alerting Receive free email alerts when new articles cite this article - sign up in the box at the top Service right corner of the article or click here.

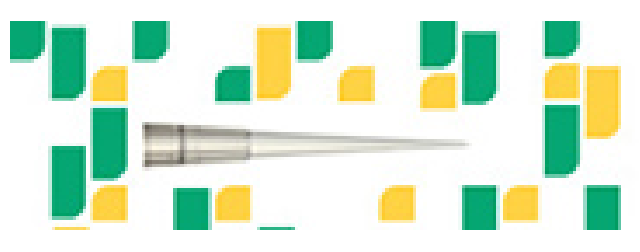

Focused on your science. 